\title{
Drivers of the Low-Cloud Response to Poleward Jet Shifts in the North Pacific in Observations and Models
}

\author{
MARK D. ZELINKA \\ Lawrence Livermore National Laboratory, Livermore, California \\ KEVIN M. GRISE \\ University of Virginia, Charlottesville, Virginia \\ STEPHEN A. KLEIN AND CHEN ZHOU ${ }^{\mathrm{a}}$ \\ Lawrence Livermore National Laboratory, Livermore, California \\ ANTHONY M. DEANGELIS ${ }^{\mathrm{b}}$ \\ University of California, Los Angeles, Los Angeles, California \\ MATTHEW W. Christensen \\ University of Oxford, Oxford, United Kingdom
}

(Manuscript received 28 February 2018, in final form 20 June 2018)

\begin{abstract}
The long-standing expectation that poleward shifts of the midlatitude jet under global warming will lead to poleward shifts of clouds and a positive radiative feedback on the climate system has been shown to be misguided by several recent studies. On interannual time scales, free-tropospheric clouds are observed to shift along with the jet, but low clouds increase across a broad expanse of the North Pacific Ocean basin, resulting in negligible changes in total cloud fraction and top-of-atmosphere radiation. Here it is shown that this lowcloud response is consistent across eight independent satellite-derived cloud products. Using multiple linear regression, it is demonstrated that the spatial pattern and magnitude of the low-cloud-coverage response is primarily driven by anomalous surface temperature advection. In the eastern North Pacific, anomalous cold advection by anomalous northerly surface winds enhances sensible and latent heat fluxes from the ocean into the boundary layer, resulting in large increases in low-cloud coverage. Local increases in low-level stability make a smaller contribution to this low-cloud increase. Despite closely capturing the observed response of large-scale meteorology to jet shifts, global climate models largely fail to capture the observed response of clouds and radiation to interannual jet shifts because they systematically underestimate how sensitive low clouds are to surface temperature advection, and to a lesser extent, low-level stability. More realistic model simulations of cloud-radiation-jet interactions require that parameterizations more accurately capture the sensitivity of low clouds to surface temperature advection.
\end{abstract}

\footnotetext{
${ }^{\text {a }}$ Current affiliation: School of Atmospheric Sciences, Nanjing University, Nanjing, China.

${ }^{\mathrm{b}}$ Current affiliations: NASA Goddard Space Flight Center, Greenbelt, and Science Systems and Applications, Inc., Lanham, Maryland.
}

Corresponding author: Mark D. Zelinka, zelinka1@llnl.gov

\section{Introduction}

Climate models robustly simulate poleward shifts of the midlatitude eddy-driven jet and storm track as the planet warms because of increased radiative forcing by carbon dioxide (Collins et al. 2013). Details of this shift vary across models, hemisphere, basin, and season (Barnes and Polvani 2013; Grise and Polvani 2016), 
however, and the theoretical reasons for the response remain debated (Simpson et al. 2014). It is reasonable to expect that poleward jet shifts will be accompanied by poleward shifts of the attendant midlatitude maxima in cloud coverage. This has led to a long-standing expectation that poleward jet shifts that accompany global warming will induce a positive cloud feedback from clouds shifting toward regions with less incoming solar radiation at the top of the atmosphere, weakening their overall shortwave cooling effect on the planet (Bony et al. 2006; Boucher et al. 2013). Indeed, global climate model (GCM) simulations of global warming produce a strong and robustly positive cloud feedback on the equatorward side of the midlatitude jets in both hemispheres that is highly suggestive of such a feedback (Zelinka et al. 2016). Moreover, recent studies have identified poleward shifts of cloud maxima in long-term cloud records that are often attributed to poleward shifts of the large-scale circulation (Bender et al. 2012; Eastman and Warren 2013; Marvel et al. 2015; Norris et al. 2016). Hence, the IPCC Fifth Assessment Report concluded that "model simulations, physical understanding and observations thus provide medium confidence that poleward shifts of cloud distributions will contribute to positive feedback, but by an uncertain amount" (Boucher et al. 2013, p. 589).

The notion that poleward jet shifts should be accompanied by poleward shifts in total cloud cover and a positive radiative feedback has, however, been recently called into question [see review by Ceppi and Hartmann (2015)]. While some models exhibit substantial positive shortwave (SW) cloud radiative effect $(\mathrm{CRE})^{1}$ anomalies averaged over the $\mathrm{SH}$ midlatitudes associated with poleward jet shifts (Grise et al. 2013), others do not (Kay et al. 2014; Wall and Hartmann 2015). Regardless, in all models, estimates of the CRE anomalies induced solely by poleward jet shifts under global warming are much smaller than the total cloud radiative response to warming at midlatitudes (Kay et al. 2014; Ceppi and Hartmann 2015; Wall and Hartmann 2015). The magnitude of cloud-induced SW heating in response to poleward jet shifts under unforced climate variability is, however, highly correlated across models with that in response to rapid poleward jet shifts from $\mathrm{CO}_{2}$ quadrupling (Grise and Polvani 2014). In general, the models with large SW heating anomalies at midlatitudes

\footnotetext{
${ }^{1} \mathrm{CRE}$ quantifies the impact of clouds on the top-of-atmosphere (TOA) energy budget relative to a hypothetical cloud-free planet, and is computed as the difference in downwelling radiation at the top of the atmosphere between all- and clear-sky conditions (Charlock and Ramanathan 1985).
}

in response to interannual poleward jet shifts are in worse agreement with observations, which exhibit a relatively muted radiative response (Grise and Polvani 2014; Ceppi and Hartmann 2015; Tselioudis et al. 2016). Together, these results suggest that the impact of jet shifts on CRE due to either a rapid adjustment to $\mathrm{CO}_{2}$ or to global warming is small.

The observed cloud response to jet shifts appears to be more complicated than a simple poleward shift leading to net radiative heating. Whereas midlevel and high clouds - which are tightly coupled to ascent in the storm tracks (Ceppi and Hartmann 2015; Grise and Polvani 2014; Li et al. 2014a,b) — do indeed move poleward with the jet, the net radiative effect of this shift is small. This is because of the close compensation between longwave and shortwave radiative effects for upper-level cloud anomalies, and because of the extensive underlying lowlevel clouds, which do not shift (Tselioudis et al. 2016) but instead tend to increase in regions vacated by upperlevel clouds that are characterized by anomalous descent and increased low-level stability (Grise and Medeiros 2016). In unforced simulations of CAM5, Kay et al. (2014) find little change in absorbed solar radiation or in cloud liquid water path in response to month-tomonth variability in $\mathrm{SH}$ jet latitude. They note that radiatively relevant low-level liquid clouds are dependent on temperature and lower-tropospheric stability, which can vary independently of jet location. Wall and Hartmann (2015) attribute the varied midlatitude jet shift-induced SW CRE responses across three aquaplanet models to differences in the response of low-level liquid clouds, which they trace to differences in their shallow convection and moist turbulence parameterizations. All of these results highlight the important role of low clouds in determining the overall cloud-radiative response to poleward jet shifts, and largely preventing the simple "drawing back of the curtains" response from being realized.

Grise and Medeiros (2016) explored the varied causes of cloud and radiation anomalies accompanying variations in the location of the midlatitude jet in both observations and models. Central to their analysis was a targeted assessment of the individual meteorological fields that change with the jet location, with a focus primarily on midtropospheric vertical motion $\left(\omega_{500}\right)$, a primary controller of high-cloud cover, and on estimated inversion strength (EIS; Wood and Bretherton 2006), a primary controller of low-cloud cover. They found that the magnitude of negative SW CRE increases too dramatically with ascent while increasing too weakly with inversion strength in the more erroneous "type I" class of phase 5 of the Coupled Model Intercomparison Project (CMIP5) models- those that have large SW 
TABLE 1. Observational datasets and their analyzed time periods.

\begin{tabular}{lll}
\hline \multicolumn{1}{c}{ Parameter } & \multicolumn{1}{c}{ Dataset } & \multicolumn{1}{c}{ Time period } \\
\hline TOA radiative fluxes & CERES-EBAF & Mar 2000-Dec 2016 \\
& Jan 1984-Dec 2009 & Jan 1982-Dec 2016 \\
Surface and atmospheric properties & NOAA-OISST & Jan 1982-Dec 2014 \\
& NOCS & Jan 1982-Oct 2016 \\
& ICOADS & Jan 1982-Dec 2016 \\
Jul 1983-Dec 2009 & Jan 1982-Dec 2009 \\
& ERA-Interim & Mar 2000-Dec 2016 \\
& ISCCP & Jul 2002-Dec 2016 \\
& PATMOS-x & Jul 2002-Apr 2012 \\
& CERES-MODIS+GEO & Sep 2002-Sep 2016 \\
& MAST-MODIS & Jun 2000-May 2013 \\
& AATSR & Jun 2006-Dec 2015 \\
\hline
\end{tabular}

absorption anomalies in response to poleward jet shifts. In contrast, the more realistic "type II" models have stronger dependence on EIS that is in better agreement with observations. This subset shows little SW warming or even SW cooling with a poleward jet shift (Grise and Polvani 2014).

However, many of the low-cloud and/or SW CRE anomalies highlighted in that study were not spatially coincident with either EIS or $\omega_{500}$ anomalies. Namely, EIS increases across the entire ocean basin in response to poleward jet shifts, whereas low-cloud fraction anomalies tend to be rather localized [e.g., cf. Fig. 1b with Fig. 2d of Grise and Medeiros (2016)]. Moreover, some increases in low-cloud fraction were attributed to anomalous descent, but increased descent actually favors less low cloud when controlling for EIS variations, at least in the subtropics (Myers and Norris 2013). Both of these suggest that other environmental factors may be important.

Our study seeks to better understand and quantify the role of various meteorological fields in controlling the low-cloud-cover response to interannual fluctuations in jet latitude over the North Pacific. While we have performed the analysis over other basins, we focus on the North Pacific here because it is the basin in which low-cloud-cover anomalies were arguably least well explained by EIS and $\omega_{500}$ in Grise and Medeiros (2016), and because ship-based observations are available over much of the domain for the full duration of satellite observations (unlike over the Southern Ocean). After breaking down the contributions to the net TOA radiation anomalies from individual cloud types and properties to elucidate why jet shifts lead to small basin-mean net CRE responses, we establish the robustness of the low-cloud response across multiple satellite instruments. Then, we quantify the meteorological drivers of these low-cloud responses using multiple linear regression.
We will show that surface cold advection is the key field governing the low-cloud response to jet shifts, and that the relative insensitivity of modeled low-cloud cover to temperature advection is the primary source of biases in models' cloud-radiative responses to jet shifts.

\section{Datasets}

We consider monthly resolved data only over the oceans that are gridded via linear interpolation to a common $2^{\circ}$ latitude by $2^{\circ}$ longitude grid. All observational datasets are listed in Table 1 , along with the period of their records that is utilized in this study.

\section{a. Observations}

\section{1) TOA RADIATIVE FLUXES}

TOA radiative fluxes come from the CERES Energy Balanced and Filled (EBAF) product, edition 4.0 (Loeb et al. 2018). CERES instruments fly on the Terra and Aqua satellites and measure filtered radiances in the shortwave $(0.3-5 \mu \mathrm{m})$, total $(0.3-200 \mu \mathrm{m})$, and infrared window $(8-12 \mu \mathrm{m})$ regions. Unfiltered radiances are determined following Loeb et al. (2001). For the EBAF product, SW and longwave (LW) TOA fluxes are adjusted within their range of uncertainty to ensure TOA fluxes satisfy global-mean energy budget constraints (Loeb et al. 2009).

In addition to the direct broadband radiative fluxes observed at the TOA by CERES, we make use of TOA fluxes from the International Satellite Cloud Climatology Project (ISCCP)-FD product (Zhang et al. 2004). Rather than being directly observed, these radiative fluxes are computed using a radiative transfer model with cloud, surface, and atmospheric properties collected by weather satellites used as input. Throughout the paper, TOA radiation anomalies are defined such 
that positive values indicate anomalous planetary radiative heating.

\section{2) Meteorological FiELdS}

Meteorological data come from ERA-Interim (Dee et al. 2011). We use 2-m temperature, sea level pressure, surface relative humidity, 1000- and $850-\mathrm{hPa}$ winds, $700-\mathrm{hPa}$ vertical pressure velocity, and $1000-$ and $700-\mathrm{hPa}$ temperature in our analysis. Sea surface temperature (SST) data come from the NOAA Optimum Interpolation (OI) SST dataset, version 2 (Reynolds et al. 2002). We use ship-based measurements of air-sea differences in temperature and saturation-specific humidity from the International Comprehensive Ocean-Atmosphere Data Set (ICOADS) $2^{\circ}$ enhanced product, release 3.0.1 (Freeman et al. 2017). Ocean-to-atmosphere latent and sensible heat fluxes come from the National Oceanography Centre, Southampton (NOCS), surface flux dataset v2.0. These fluxes are derived from ICOADS v2.4 ship measurements (Berry and Kent 2009, 2011).

\section{3) Cloud FRACTION}

The ISCCP cloud dataset is composed of data collected by a suite of geostationary and polar-orbiting weather satellites. We use the 3-hourly (D1) dataset to create monthly joint histograms of cloud fraction in seven cloud-top pressure and six cloud optical depth bins following Rossow and Schiffer (1999). As is done with the GCM-oriented ISCCP product (Pincus et al. 2012), we include only daytime observations and compute averages over the entire month at once rather than first averaging each of the eight daily observation times together. Thus the dataset is consistent with that produced by the ISCCP simulator.

We use histograms of cloud fraction from the Pathfinder Atmospheres-Extended (PATMOS-x) dataset. These data come from all five channels of the Advanced Very High Resolution Radiometer (AVHRR) sensor on board the polar-orbiting platforms of NOAA and EUMETSAT. Cloud detection is based on six Bayesian classifiers derived from Cloud-Aerosol Lidar and Infrared Pathfinder Satellite Observations (CALIPSO; Heidinger et al. 2012), and the retrieval is based on an optimal estimation approach (Heidinger and Pavolonis 2009). Cloud-top pressure and cloud emissivity are retrieved using two IR channels at all times of day, and cloud optical depth is obtained from solar channels during daytime (Walther and Heidinger 2012; Heidinger et al. 2012, 2014). We make use of the 1330 UTC NOAA PATMOS-x dataset provided by the GEWEX cloud assessment (Stubenrauch et al. 2013).

We use joint histograms of cloud fraction as a function of seven optical depth and seven cloud-top pressure bins from the Moderate Resolution Imaging Spectroradiometer (MODIS; Salomonson et al. 1989). MODIS is a whisk-broom scanning radiometer with 36 channels covering $0.42-14.24 \mu \mathrm{m}$, flying on both the Terra and Aqua spacecrafts. We use the L3 gridded cloud product (MYD08_M3) from the latest MODIS release (Collection 6), which is described in detail in Baum et al. (2012). To avoid radiometric calibration drift issues identified by Yue et al. (2017), we only make use of data from the Aqua MODIS instrument. To distinguish this dataset, which is produced by the MODIS Atmosphere Science Team (MAST), from the CERES-MODIS+GEO product described below, we hereafter refer to it as "MAST-MODIS."

The CERES CldTypHist Ed4A product provides MODIS and geostationary satellite cloud properties stratified by cloud pressure and optical depth (Wielicki et al. 1996). The product utilizes Terra and Aqua MODIS cloud properties that are based on the CERES cloud working group SYN1deg Ed4A retrievals (Minnis et al. 2011), supplemented with 1-hourly geostationary cloud retrievals equatorward of $60^{\circ}$ latitude to provide diurnal coverage. Cloud properties are aggregated into the three cloud-top pressure and three optical depth bins commonly reported in ISCCP-D2 cloud products and are reported separately for liquid and ice clouds, which we sum to get the total cloud fraction. We will hereafter refer to this dataset as "CERES-MODIS+GEO."

We use cloud fraction derived from measurements taken by the Advanced Along-Track Scanning Radiometer (AATSR) on EnviSat, which is available from July 2002 through April 2012. These data are provided by the European Space Agency Climate Change Initiative (CCI; Hollmann et al. 2013), and contain cloud fraction derived using the Community Cloud retrieval for Climate framework (Sus et al. 2018; McGarragh et al. 2018) for low, midlevel, and high clouds, with bin boundaries at 680 and $440 \mathrm{hPa}$. More details on the dataset can be found in Stengel et al. (2017).

We make use of effective cloud fraction - the product of cloud fraction and emissivity-from the Atmospheric Infrared Sounder (AIRS). The AIRS instrument suite is composed of a hyperspectral infrared instrument with 2378 channels spanning 3.7 to $15 \mu \mathrm{m}$ and the Advanced Microwave Sounding Unit flying on board Aqua (Aumann et al. 2003; Chahine et al. 2006). Version 6 of the AIRS product (Kahn et al. 2014) provides the effective cloud fraction for low, midlevel, and high clouds, with bin boundaries at 680 and $440 \mathrm{hPa}$. We average data from ascending and descending orbits into a single monthly mean field.

We use cloud fraction retrieved by the Multiangle Imaging SpectroRadiometer (MISR) on board Terra 
(Diner et al. 2005). MISR consists of nine cameras pointed at different view angles collecting radiances in four narrow spectral bands located at $443,555,670$, and $865 \mathrm{~nm}$. We use the level 3 CFMIP-Obs MISR cloud observations for climate model evaluation product, version 6 (Marchand et al. 2010; Marchand and Ackerman 2010), which provides joint histograms of cloud fraction as a function of 15 cloud-top height (CTH) and seven cloud optical depth bins. Following Marchand (2013), we separate high, midlevel, and low clouds using CTH boundaries of 3 and $7 \mathrm{~km}$.

Finally, we use cloud fraction retrieved from the Cloud-Aerosol Lidar with Orthogonal Polarization (CALIOP) instrument, which is a two-wavelength (532 and $1064 \mathrm{~nm}$ ) polarization lidar (Winker et al. 2009) on the CALIPSO satellite. We use the "MapLowMidHigh" cloud fraction field provided as part of the GCM-Oriented CALIPSO Cloud Product (CALIPSO-GOCCP) v3.0 prepared for the Observations for Model Intercomparisons Project (obs4MIPs; Chepfer et al. 2010), which contains low (below $3.2 \mathrm{~km}$ ), midlevel $(3.2$ to $6.5 \mathrm{~km}$ ), and high (above $6.5 \mathrm{~km}$ ) cloud fractions. These fields are fully consistent with those produced by the CALIPSO simulator utilized in climate models.

Because cloud cover retrieved from passive satellites can suffer from obscuration effects in which upper-level clouds mask lower-level clouds, we estimate the "true" low-cloud cover (LCC) after adjusting for overlap by nonlow clouds assuming random overlap statistics (Morcrette and Fouquart 1986; Rozendaal et al. 1995):

$$
\mathrm{LCC}=\frac{f_{\text {low }}}{1-f_{\text {mid }}-f_{\text {hi }}} .
$$

Here, $f_{\text {low }}, f_{\text {mid }}$, and $f_{\text {hi }}$ are the fraction of the scene covered by low, midlevel, and high clouds, respectively, as viewed directly from spaceborne instruments. For AATSR and AIRS, $f_{\text {low }}, f_{\text {mid }}$, and $f_{\text {hi }}$ are provided directly in the datasets used. For ISCCP, PATMOS-x, MAST-MODIS, CERES-MODIS+GEO, and MISR, these are computed by summing the respective histograms over all optical depths for the relevant cloud-top pressure or altitude bins.

\section{b. Global climate models}

We make use of unforced preindustrial control ("piControl") simulations from 35 global climate models taking part in CMIP5 (Taylor et al. 2012). We consider all of the same quantities in GCMs as we do in observations, but cloud fraction diagnostics from climate models are in general not directly comparable to cloud fraction retrieved from satellite sensors. Therefore we use two approaches to facilitate model-observation comparison of low-cloud coverage. First, for the GCMs that have implemented the CFMIP Observation Simulator Package (COSP; Bodas-Salcedo et al. 2011), we use output from the ISCCP simulator (Klein and Jakob 1999; Webb et al. 2001) and from the CALIPSO simulator (Chepfer et al. 2008). ISCCP simulator-derived low-cloud cover, $\mathrm{LCC}_{I}$, is computed from the "clisccp" histograms as described above, while that from the CALIPSO simulator, $\mathrm{LCC}_{C}$, is reported directly ("cllcalipso"). Low-cloud coverage from these can be compared directly to their observational counterparts.

Second, we derive a proxy for LCC from the standard vertical profile of monthly mean cloud fraction diagnosed by each model ("cl") as the maximum of cloud fraction between the surface and $680 \mathrm{hPa}$ at each grid point (Noda and Satoh 2014; Zhou et al. 2015). This field is available from all models, regardless of whether they implemented COSP. We refer to this as $\mathrm{LCC}_{V}$, where the subscript $V$ denotes LCC calculated from cloud fraction at vertical levels. Interannual $\mathrm{LCC}_{V}$ anomalies are well correlated with ISCCP simulator-derived LCC anomalies (Zhou et al. 2015), so it serves as a useful proxy for LCC. We confirm the consistency among the various model-derived LCC fields in our results below.

Because COSP output is usually available for at least 40 years, often broken up into two noncontiguous $20-\mathrm{yr}$ periods, we use model output from the period of time containing COSP output. For models without COSP output, we use the final 40 years of the piControl run. Table 2 lists the models used and the duration of COSP output utilized, if applicable.

\section{Methodology}

In this study, we attempt to understand and explain the cloud and net TOA radiation response to interannual fluctuations in the latitude of the midlatitude eddy-driven jet over the North Pacific Ocean, defined as spanning from $135^{\circ} \mathrm{E}$ to $125^{\circ} \mathrm{W}$. We focus primarily on the impact of clouds on net TOA radiation rather than its LW and SW components because we are motivated by the implications of a potential jet shift-related cloud feedback for climate sensitivity, which is more unambiguously related to the net planetary energy budget. Because nonlow clouds tend to have counteracting LW and SW radiative effects, this leads inevitably to a focus on the response of low clouds to jet shifts.

To derive these responses, we perform ordinary least squares linear regression of interannual anomalies in radiation, clouds, and relevant meteorological fields on interannual anomalies in jet latitude. We will hereafter refer to these as "responses to poleward jet shifts," with the acknowledgment that this is shorthand for the typical anomalies present when the midlatitude jet is in an 
TABLE 2. Global climate models used in this study. Availability of COSP output is noted. The "r1i1p1" ensemble member of each model's preindustrial control run is used. For CCSM4, we use the "r3i1p1" member, as it is the only member for which COSP output is available.

\begin{tabular}{|c|c|c|}
\hline & \multicolumn{2}{|c|}{$\begin{array}{c}\text { Number of years of COSP } \\
\text { output used }\end{array}$} \\
\hline & ISCCP & CALIPSO \\
\hline ACCESS1.0 & 0 & 0 \\
\hline ACCESS1.3 & 0 & 0 \\
\hline BNU-ESM & 0 & 0 \\
\hline CCSM4 & 40 & 0 \\
\hline CESM1(BGC) & 0 & 0 \\
\hline CESM1(CAM5) & 0 & 0 \\
\hline CESM1(FASTCHEM) & 0 & 0 \\
\hline CESM1(WACCM) & 0 & 0 \\
\hline CMCC-CESM & 0 & 0 \\
\hline CSIRO Mk3.6.0 & 0 & 0 \\
\hline CanESM2 & 40 & 40 \\
\hline FGOALS-g2 & 0 & 0 \\
\hline FGOALS-s2 & 0 & 0 \\
\hline GFDL CM3 & 0 & 0 \\
\hline GFDL-ESM2G & 0 & 0 \\
\hline GFDL-ESM2M & 0 & 0 \\
\hline GISS-E2-H & 0 & 0 \\
\hline GISS-E2-R & 0 & 0 \\
\hline GISS-E2-R-CC & 0 & 0 \\
\hline HadGEM2-ES & 40 & 40 \\
\hline IPSL-CM5A-LR & 0 & 0 \\
\hline IPSL-CM5A-MR & 40 & 40 \\
\hline IPSL-CM5B-LR & 0 & 0 \\
\hline MIROC-ESM & 20 & 40 \\
\hline MIROC-ESM-CHEM & 20 & 20 \\
\hline MIROC5 & 40 & 40 \\
\hline MPI-ESM-LR & 40 & 40 \\
\hline MPI-ESM-MR & 0 & 0 \\
\hline MPI-ESM-P & 0 & 0 \\
\hline NorESM1-M & 0 & 0 \\
\hline NorESM1-ME & 0 & 0 \\
\hline BCC_CSM1.1 & 0 & 0 \\
\hline BCC_CSM1.1(m) & 0 & 0 \\
\hline FIO-ESM & 0 & 0 \\
\hline INM-CM4.0 & 0 & 0 \\
\hline
\end{tabular}

anomalously poleward position on the interannual time scale. We focus in this paper on responses computed using all months of the year, but discuss seasonal dependence of the results below.

We compute the jet latitude for the North Pacific basin by first locating the latitude at which the zonalmean $850-\mathrm{hPa}$ zonal wind within the basin reaches its maximum value. Then we identify the latitude of maximum wind speed at a resolution of $0.01^{\circ}$ using a cubic spline fit following Barnes and Polvani (2013). The interannual standard deviation of North Pacific jet latitude is $3.0^{\circ}$ over the period $1982-2016$. Therefore, all responses to a $1^{\circ}$ jet shift shown below should be multiplied by 3 to estimate the response to a typical fluctuation in jet location on interannual time scales.

In addition to the standard meteorological fields noted in the previous section, there are two environmental fields that we derive. First, to measure the strength of lower-tropospheric atmospheric stability, we compute the estimated inversion strength (EIS; Wood and Bretherton 2006). This is expected to have an important control on LCC because a stronger capping inversion opposes entrainment of drier free-tropospheric air, thereby favoring a moister and cloudier boundary layer (Klein and Hartmann 1993; Wood and Bretherton 2006).

Second, we estimate surface temperature advection $\left(T_{\text {adv }}\right)$, which is meaningful for low clouds because it serves as a proxy for the upward surface buoyancy flux (i.e., the potential of the ocean surface to drive atmospheric boundary layer turbulence). It is computed as the product of the $1000-\mathrm{hPa}$ winds with the horizontal gradient of SST (Klein et al. 1995; Norris and Iacobellis 2005; Mansbach and Norris 2007). This is done separately for the zonal and meridional components; the total surface temperature advection is their sum.

Surface temperature advection derived as the product of monthly resolved winds and SST gradients may not fully capture the true monthly fluctuations in surface buoyancy flux because of substantial submonthly variability in winds and air-sea temperature differences at mid- and high latitudes (Miyamoto et al. 2018). As an independent check that $T_{\text {adv }}$ serves as a useful proxy for surface buoyancy flux, we correlated interannual anomalies in $T_{\text {adv }}$ at every location in the basin with coincident anomalies in surface buoyancy flux derived as a linear combination of latent and sensible heat fluxes (Randall 1980). Surface cold advection and surface buoyancy flux are positively correlated throughout the North Pacific basin, with largest correlations $(r=0.6)$ occurring in an eastern North Pacific region where most of our subsequent analysis is focused (not shown). We conclude that over the majority of the basin, $T_{\text {adv }}$ is a useful indicator of the surface buoyancy flux, but stress that it is a statistical measure of the actual physical mechanisms that are occurring on submonthly time scales.

Usage of SST gradients in estimating $T_{\text {adv }}$ relies on the assumption that air-sea temperatures closely track each other, which may be less valid at mid- and high latitudes than it is at low latitudes. We find that our results are largely insensitive to whether surface temperature gradients based on 2-m or 1000-hPa temperatures are used in place of SSTs in computing $T_{\text {adv }}$ (not shown). Results are also insensitive to whether $10-\mathrm{m}$ winds are used instead of $1000-\mathrm{hPa}$ winds.

In all analyses, we remove the climatological annual cycle and any long-term trend before regressing any field 
Cloud-Induced Net TOA Radiation Anomalies in Response to Jet Shift

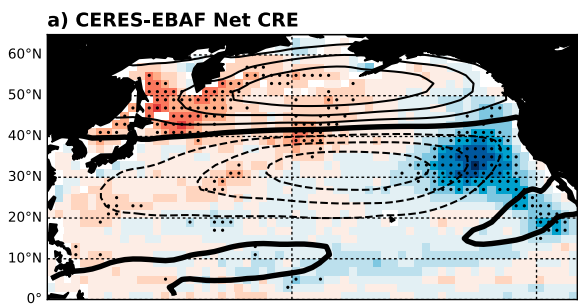

c) Due to Non-low Clouds

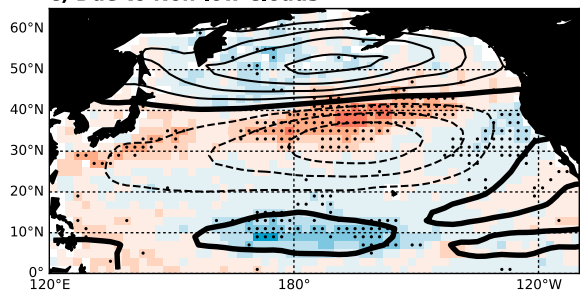

e) Zonal Mean Cloud-Induced Rad. Anomalies

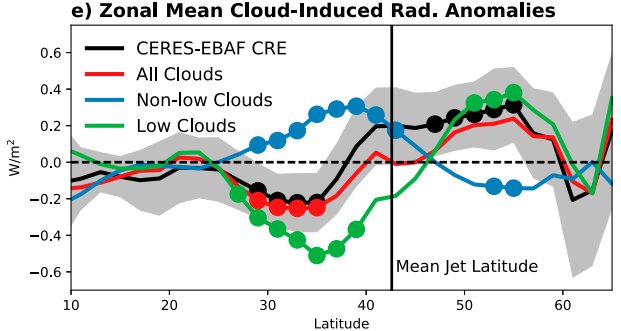

b) Due to All Clouds

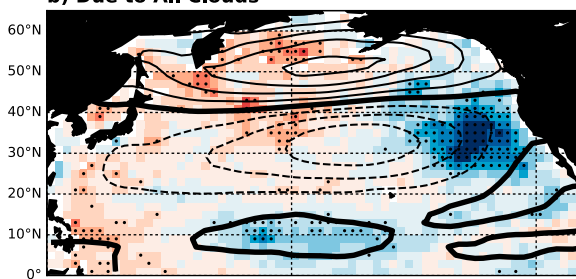

d) Due to Low Clouds
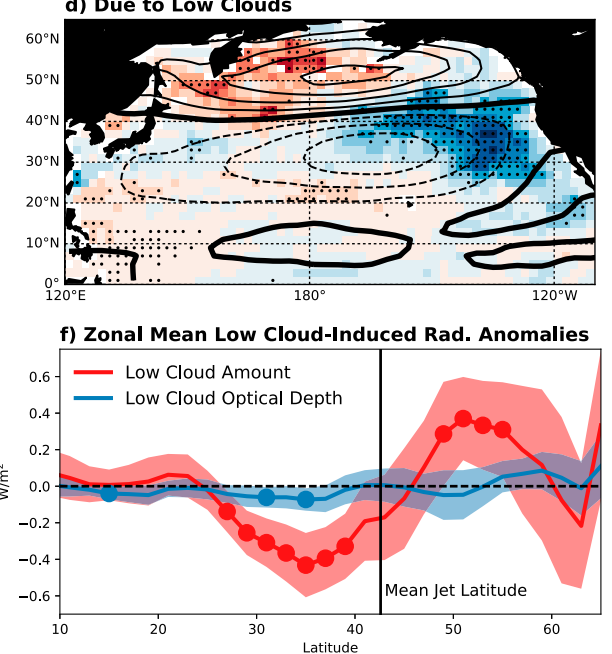

FIG. 1. Anomalies in (a) CERES net CRE and in TOA net radiation induced by (b) all clouds, (c) nonlow clouds, and (d) low clouds in response to a $1^{\circ}$ poleward jet shift. Anomalies in (b)-(d) are derived using cloud radiative kernels and MAST-MODIS cloud fraction histogram anomalies. Stippling indicates regression slopes that are statistically significant at the $95 \%$ confidence level. Overlain in (a)-(d) in contours are anomalies in the $850-\mathrm{hPa}$ zonal wind, with a contour interval of $0.2 \mathrm{~m} \mathrm{~s}^{-1}$ and the zero contour in bold. (e) Response of the zonal-mean quantities to a $1^{\circ}$ poleward jet shift, with statistically significant (at $95 \%$ confidence) responses indicated by filled circles. Shading represents the $2 \sigma$ uncertainty in zonal-mean net CRE regression slope. Other slope uncertainties are omitted for clarity. (f) Amount and optical depth components of the low-cloud-induced radiation anomalies. Shading represents the $2 \sigma$ uncertainty in zonal-mean regression slopes. All uncertainties are estimated using degrees of freedom that account for temporal autocorrelation.

on the jet latitude. Both the annual cycle and the longterm trend (estimated using ordinary least squares regression) are computed for the period of overlap between the jet latitude time series and the field of interest. Regression slopes that are statistically significant at the $95 \%$ confidence level are determined using the two-tailed Student's $t$ test, with degrees of freedom that account for temporal autocorrelation in each dataset (Bretherton et al. 1999).

\section{Results}

\section{a. Why do observed interannual jet shifts lead to small basin-mean net CRE responses?}

In response to a $1^{\circ}$ poleward shift of the jet, net cloud radiative effect, which is negative on average throughout the basin, weakens in the northwestern part of the basin and strengthens in the southeastern part of the basin, especially just off the west coast of North America (Fig. 1a). Results derived using ISCCP-FD data are in qualitative agreement with those shown from CERES (appendix A and Fig. A1a). Rather than exhibiting a north-south dipole with a large positive CRE anomaly to the south and a smaller negative net CRE anomaly to the north, as would be expected if clouds simply shifted poleward with the jet, the anomalous structure is very zonally asymmetric and does not show any obvious correspondence to the anomalous $850-\mathrm{hPa}$ zonal wind pattern, which is overlain in contours.

Given that CRE anomalies in this region can be caused by changes in both the amount and optical depth of clouds at all vertical levels, and that the relative importance of variations in environmental factors likely differs depending on the cloud type and property change of interest (Norris and Iacobellis 2005; Li et al. 2014a; Terai et al. 2016; Ceppi et al. 2016), it is important to 
determine which cloud types and properties are causing these observed CRE anomalies. To do so, we compute cloud-induced radiation anomalies using cloud radiative kernels and anomalies in cloud fraction-both as functions of cloud-top pressure and visible optical depthand break down their contributions from changes in amount, altitude, and optical depth, for both low$(\mathrm{CTP}>680 \mathrm{hPa})$ and free-tropospheric $(\mathrm{CTP} \leq$ $680 \mathrm{hPa}$ ) clouds (Zelinka et al. 2012a,b, 2016). Cloudinduced radiation anomalies computed using kernels applied to MAST-MODIS cloud fraction anomalies (Fig. 1b) agree closely with the CERES net CRE anomalies (Fig. 1a), indicating that CRE anomalies are caused primarily by anomalies in clouds rather than in noncloud fields. With the exception of the negative net CRE anomalies at $10^{\circ} \mathrm{N}$ near the date line, which are primarily due to free-tropospheric clouds (Fig. 1c), net CRE anomalies over the vast majority of the basin are primarily driven by low-cloud anomalies (Fig. 1d).

Zonally averaging across the North Pacific basin, there are small but statistically significant negative net $\mathrm{CRE}$ anomalies on the equatorward side of the climatological jet and small but statistically significant positive anomalies on the poleward side of the climatological jet (Fig. 1e). Hence, not only do low-cloud-induced radiation anomalies strongly oppose those of upper-level clouds, they dominate the overall net radiative signature of the jet shift, leading to a north-south dipole that is opposite to what would be expected if the cloud field simply shifted poleward. Breaking the low-cloud component down even further reveals that negative radiative anomalies on the equatorward side of the jet are due to local increases in low-cloud amount, and positive anomalies on the poleward side are due to decreases in low-cloud amount (Fig. 1f). Low-cloud optical depth changes in response to a jet shift are generally indistinguishable from zero in the zonal mean.

In summary, the large northwest-southeast dipole in the net CRE response to a poleward jet shift, which averages out to a near-zero basinwide net radiation anomaly $\left(-0.02\right.$ and $0.01 \mathrm{~W} \mathrm{~m}^{-2}$ for CERES-EBAF and ISCCP-FD, respectively), is primarily driven by lowcloud amount changes. Hereafter, we will focus on understanding the causes of these low-cloud anomalies, particularly the increase in low clouds in the eastern part of the basin.

\section{b. How robust is the low-cloud response to jet shifts?}

We establish the robustness of these cloud anomalies across datasets that span different time periods and rely on different sensors (passive vs active), orbital configuration (polar-orbiting vs geostationary), retrieval algorithms, and spectral channels (IR only, visible only, and combined IR visible). In Fig. 2 we show the LCC response to a $1^{\circ}$ poleward jet shift from all eight cloud datasets. LCC from passive retrievals has been adjusted to account for obscuration effects following Eq. (1).

LCC anomalies are in excellent qualitative agreement across these eight observational datasets, and indicate a robust LCC increase across a large swath of the eastern North Pacific and a robust decrease in the northwestern portion of the basin. Rather than simply being revealed by poleward-shifted high clouds vacating the overlying atmosphere, these robust increases in obscurationadjusted LCC occur over a broader region than is implied by the direct satellite view of low clouds. Despite the much shorter record, the active satellite measurements from CALIPSO qualitatively confirm the pattern of LCC anomalies seen in the passive sensors (Fig. 2h).

In all cases, a strong spatial correspondence is apparent between increased LCC and anomalous meridional surface cold advection, which is overlain in contours. The boundary between anomalous cold and warm advection (bold contour) roughly demarcates the boundary between positive and negative LCC anomalies. This relationship will be explored further below.

ISCCP often erroneously assigns clouds to midlevels when optically thin high clouds are present above low clouds (Marchand et al. 2010; Mace et al. 2011) or when low clouds are present under strong temperature inversions (Garay et al. 2008). However, we find that ISCCP LCC anomalies are in excellent agreement with anomalies in obscuration-adjusted low plus midlevel cloud cover (not shown), indicating that ISCCP is not underestimating the true LCC response.

\section{c. How does the relevant large-scale meteorology respond to jet shifts?}

Several meteorological fields that have been demonstrated to impact LCC exhibit regional anomalies in response to a poleward jet shift (Fig. 3). A poleward jet shift is associated with anomalously high sea level pressure throughout most of the basin, with maximum anomalies exceeding $1 \mathrm{hPa}$ near about $45^{\circ} \mathrm{N}, 160^{\circ} \mathrm{W}$ (Fig. 3a). This is consistent with a poleward shift of the subtropical high as the circulation retreats poleward. Associated with this are anomalous anticyclonic surface winds, with anomalous northerlies in the southeastern part of the domain and anomalous southerlies in the northwestern part of the domain (Fig. 3c). These ERAInterim wind anomalies are confirmed in ICOADS data (not shown).

We find that interannual variations in surface temperature advection north of $20^{\circ} \mathrm{N}$ are almost entirely driven by variations in winds rather than variations in SST gradients (not shown). Therefore, the aforementioned pattern of 
a) ISCCP

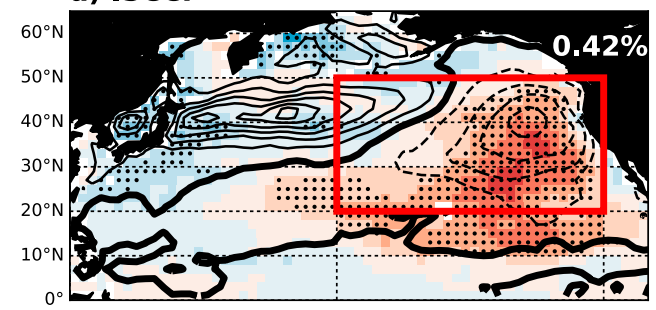

c) MAST-MODIS

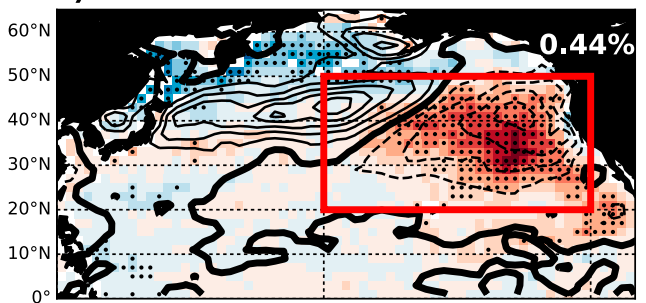

e) AATSR

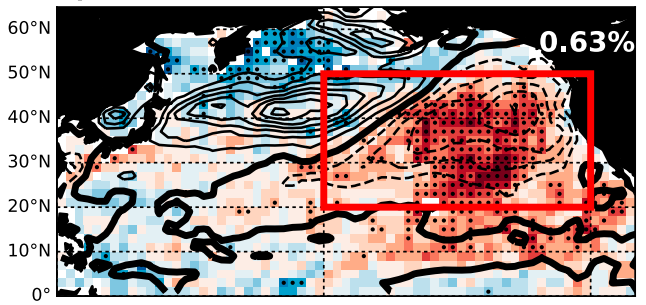

g) MISR

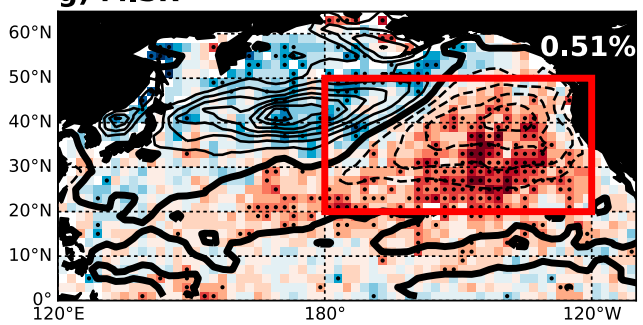

b) PATMOS-X

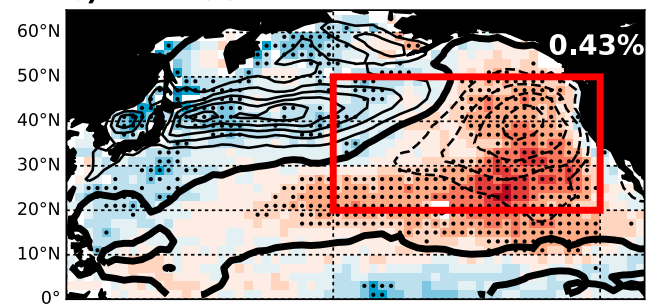

d) CERES-MODIS+GEO

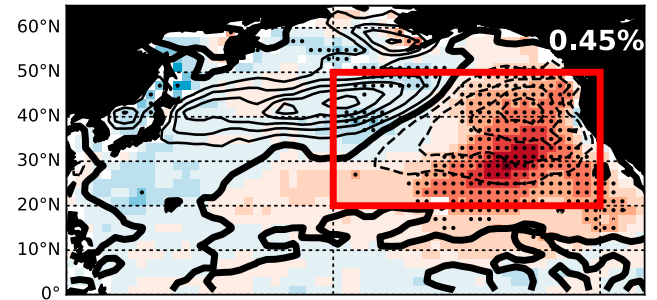

f) AIRS

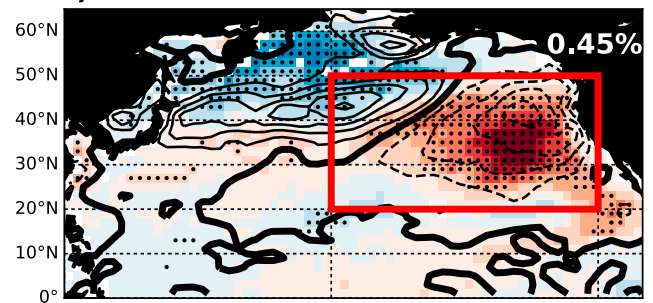

h) CALIPSO-GOCCP

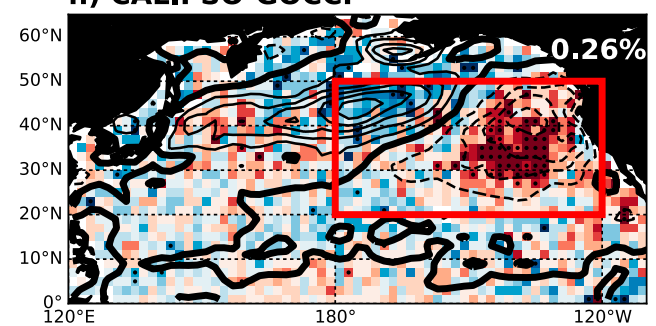

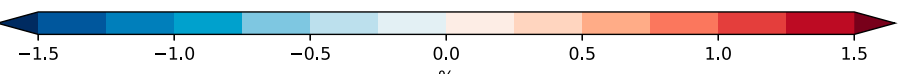

FIG. 2. Low-cloud-cover anomalies in response to a $1^{\circ}$ poleward jet shift observed by (a) ISCCP, (b) PATMOS-x, (c) MAST-MODIS, (d) CERES-MODIS+GEO, (e) AATSR, (f) AIRS, (g) MISR, and (h) CALIPSO-GOCCP. Stippling indicates regression slopes that are statistically significant at the $95 \%$ confidence level. Overlain in black contours are anomalies in meridional $T_{\text {adv }}$, with a contour interval of $0.04 \mathrm{~K} \mathrm{day}^{-1}$ and the zero contour in bold. The $T_{\mathrm{adv}}$ anomalies in each panel are computed over the period of time coincident with the corresponding satellite dataset (Table 1). The red box denotes the region over which the anomalies shown in Fig. 5 are computed, and the average LCC anomalies in this region are displayed in white font over North America.

anomalous meridional flow is reflected in the pattern of anomalous surface temperature advection (Fig. 3e), which is largely set by its meridional component (Fig. 3f). Specifically, anomalous cold advection occurs in a triangular region bounded on the east by the North American coast and on the west by a southwest-to-northeast line passing through the center of the anomalous anticyclone. Anomalous cold advection is particularly pronounced west of California at around $40^{\circ} \mathrm{N}, 135^{\circ} \mathrm{W}$. Anomalous warm advection is maximized along the Kuroshio, where anomalous southerlies pass over a sharp meridional SST gradient. Despite the fact that zonal wind anomalies are larger than meridional wind anomalies (Figs. 3b,c), $T_{\text {adv }}$ by the anomalous zonal wind (not shown) is much smaller than that by the meridional winds (Fig. 3f), owing to the much larger meridional gradients in SST.

Associated with anomalous cold advection in the eastern part of the basin are anomalous sensible and latent heat fluxes from ocean to atmosphere (Figs. 3h,i), as expected from studies of cold-air outbreaks (Bunker 


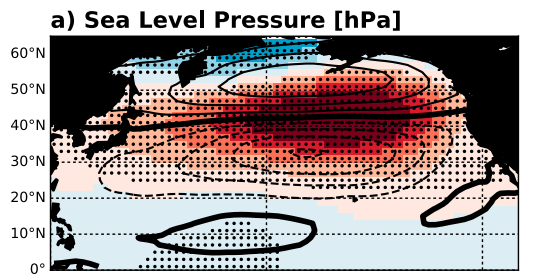

d) EIS [K]

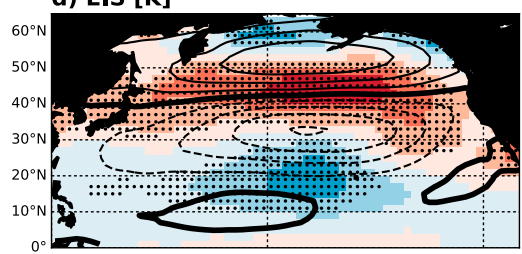

g) $\omega_{700}[\mathbf{h P a} /$ day $]$

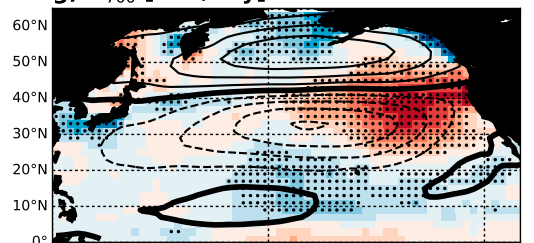

j) SST [K]

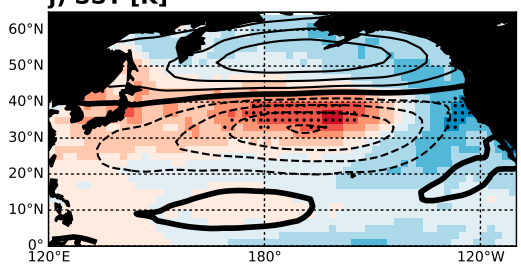

b) Sfc. Zonal Wind [m/s]

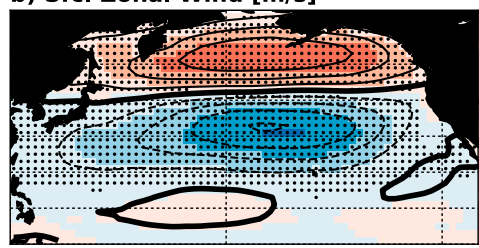

e) Sfc. Temp. Advection [K/day]

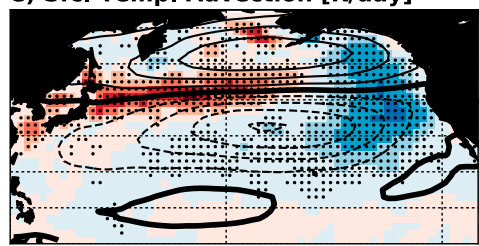

h) Sea-Air Sensible Heat Flux $\left[\mathrm{W} / \mathrm{m}^{2}\right]$

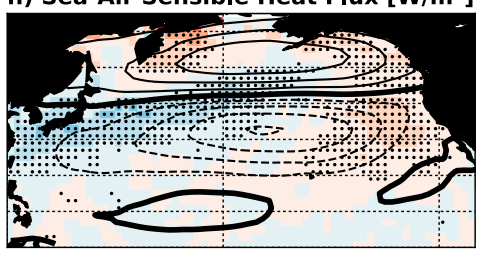

k) Sea-Air Temp. Difference [K]

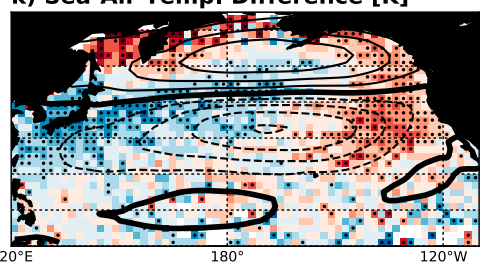

c) Sfc. Meridional Wind $[\mathrm{m} / \mathrm{s}]$

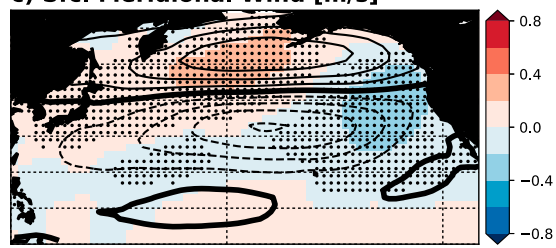

f) N-S Sfc. Temp. Advection [K/day]

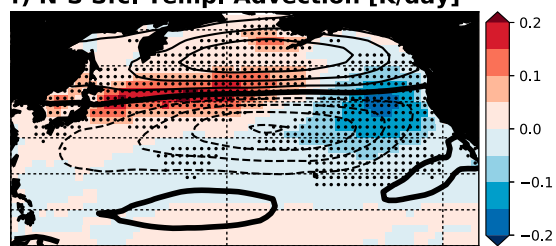

i) Sea-Air Latent Heat Flux $\left[\mathrm{w} / \mathrm{m}^{2}\right]$

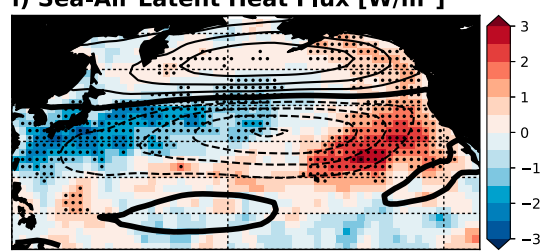

I) $q_{s}-q[g / k g]$

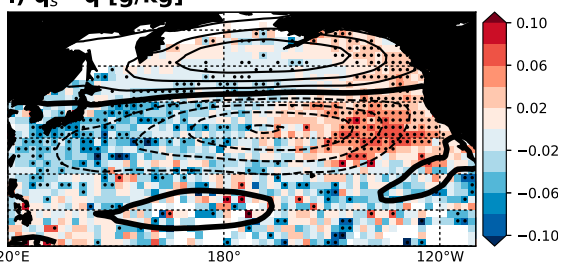

FIG. 3. Anomalies in (a) sea level pressure, surface (b) zonal and (c) meridional wind, (d) EIS, temperature advection by the (e) total and (f) meridional surface winds, (g) $\omega_{700}$, sea-to-air (h) sensible and (i) latent heat flux, (j) SST, and air-sea differences in (k) temperature and (l) saturation specific humidity in response to a $1^{\circ}$ poleward jet shift. Stippling indicates regression slopes that are statistically significant at the $95 \%$ confidence level. Overlain black contours are $850-\mathrm{hPa}$ zonal wind anomalies with a contour interval of $0.2 \mathrm{~m} \mathrm{~s}^{-1}$. Color bars apply to all three panels of their respective rows.

1960; Grossman and Betts 1990; Brummer 1996). These anomalous fluxes are driven by large air-sea differences in temperature and saturation-specific humidity (Figs. $3 \mathrm{k}, \mathrm{l}$ ) as relatively cold and dry air passes southward over the relatively warm ocean surface in this region. The opposite is the case over the Kuroshio region, where the typically large sea-to-air fluxes are reduced by anomalously warm and moist poleward-flowing air. These results imply that $T_{\text {adv }}$ is a useful proxy for surface latent and sensible heat fluxes that are relevant for LCC. Because SST and surface winds are better observed than surface heat fluxes, we will hereafter rely on $T_{\text {adv }}$ in our analysis of low-cloud-controlling factors.

Other relevant meteorological factors are perturbed when the jet shifts poleward. As highlighted in Grise and Medeiros (2016), EIS anomalies exhibit a north-south tripole across most of the North Pacific basin, with increased stability between about $30^{\circ}$ and $55^{\circ} \mathrm{N}$ across the basin and decreased stability south of $30^{\circ} \mathrm{N}$ in the central part of the basin (Fig. 3d). These EIS anomalies are closely matched by $700-\mathrm{hPa}$ temperature anomalies throughout most of the basin (not shown). Anomalously high stability also extends along the entire coast of North America from $20^{\circ}$ to $50^{\circ} \mathrm{N}$ despite the presence of negative 700-hPa temperature anomalies. EIS increases in this region are caused by locally negative SST anomalies (Fig. 3j). A region of anomalous descent occurs in the northeastern Pacific, surrounded by regions of weaker anomalous ascent (Fig. 3g).

\section{d. What are the key environmental factors driving the low-cloud response to jet shifts?}

As discussed in the previous section, many meteorological fields respond to a poleward jet shift, and may therefore cause the LCC anomalies shown in Fig. 2. To better attribute LCC responses, we decompose LCC anomalies into contributions from individual cloudcontrolling factors. We posit that each of these contributions can be expressed as the product of 1) the sensitivity of LCC to that meteorological field holding 
the others fixed and 2) the actual response of that meteorological field. Mathematically, this can be expressed as

$$
\Delta \mathrm{LCC}=\sum_{i}\left(\frac{\partial \mathrm{LCC}}{\partial x_{i}}\right) \Delta x_{i}+\varepsilon
$$

where $x_{i}$ are individual cloud-controlling factors and $\varepsilon$ is a residual. Such an approach is employed in several previous studies (Qu et al. 2014, 2015; Seethala et al. 2015; Zhou et al. 2015; Myers and Norris 2016) and is reviewed in Klein et al. (2017). The partial derivatives are computed by multiple linear regression analysis, after first removing the climatological annual cycle and any long-term trend from both LCC and predictor variables. The $\Delta x_{i}$ terms are the responses of cloud-controlling factors to a $1^{\circ}$ poleward shift of the jet latitude.

Having considered two-variate and three-variate regression models including all possible combinations of 10 commonly used low-cloud-controlling factors, we found that a bivariate model containing only EIS and $T_{\text {adv }}$ explained the largest LCC variance (49\% averaged across satellite datasets) in our target region using the minimum number of predictors. Our target region is $20^{\circ}-50^{\circ} \mathrm{N}, 180^{\circ}-120^{\circ} \mathrm{W}$, which encompasses the primary region of LCC increases in response to poleward jet shifts. This region, indicated by red boxes in Fig. 2, will hereafter be referred to as the "red box region." Further details of this selection process are provided in appendix B.

Clouds at a given location are affected by upwind environmental conditions owing to the lag of up to several days between anomalies in environmental conditions and boundary layer properties (Klein et al. 1995). In some regions where the wind is steady, including the eastern North Pacific, this will be a location about 300$500 \mathrm{~km}$ away. To better capture the nonlocal effect of meteorology on clouds, we perform multiple linear regression analysis on fields that have been averaged into $10^{\circ}$ latitude-longitude boxes rather than at the data's native resolution.

If predictor variables are too strongly correlated with each other, they will not add skill to the regression model and are considered redundant. In such a situation of substantial multicollinearity, the derived sensitivity of LCC to individual predictors may change erratically in response to small changes in the model or the dataset, possibly giving invalid results about individual predictors. Variance inflation factors (VIFs) quantify how much larger the variance of an estimated regression coefficient is compared with what it would be if that variable were uncorrelated with the other model predictors. VIFs exceeding 5 or 10 are commonly considered to indicate that substantial multicollinearity is present. In all results shown below, VIFs rarely exceed 3 in any grid box (not shown). The relative stability of our regression coefficients across satellite datasets further supports their robustness.

In Figs. 4a and 4d, we show the ISCCP LCC sensitivity to the two cloud-controlling factors in our regression model, EIS and $T_{\text {adv }}$. Having normalized each cloudcontrolling factor by the standard deviation of its deseasonalized time series in each $10^{\circ}$ box, the LCC sensitivities can be directly compared across predictors, as they represent the sensitivity of low-cloud coverage to a typical interannual anomaly in each field holding the other field fixed. These standard deviations are computed over the full available record of the cloudcontrolling factor so as to be the same for all satellite cloud datasets, regardless of their duration of overlap.

LCC increases with EIS at nearly every grid box, though the sensitivities are not statistically significant over much of the southern part and extreme northern part of the basin (Fig. 4a). This is consistent with Naud et al. (2016), who found that the climatological correlation between LCC and EIS for undisturbed and weakly subsiding regions in the tropics and midlatitudes (Wood and Bretherton 2006) also holds in post-coldfrontal regimes with strong subsidence and highly disturbed dynamical conditions.

At every grid box, LCC increases with increasing cold advection (Fig. 4d), as has been highlighted by previous authors (Deser et al. 1993; Klein et al. 1995; Norris 1998a,b; Mansbach and Norris 2007; Myers and Norris 2015; Seethala et al. 2015; Fletcher et al. 2016). The derived sensitivities are statistically significant at nearly every location. As noted above, the reasons for this relationship involve enhanced sea-to-air sensible and latent heat fluxes when colder, drier air passes over relatively warmer water, favoring low-cloud formation. The formation of fog under conditions of strong surface warm advection, which would give a relationship of the opposite sign, is apparently not manifest in calculations performed on these spatial scales.

Black contours overlain in Figs. $4 \mathrm{a}$ and $4 \mathrm{~d}$ are the actual responses of each cloud-controlling factor to a $1^{\circ}$ poleward shift of the jet. Since the responses are normalized by the standard deviations of their entire time series in each box, they are expressed in units of standard deviation $\sigma$. When multiplied by the previously discussed LCC sensitivities, they produce estimates of the contribution of each cloud-controlling factor to the actual LCC response (Figs. 4b,e).

As noted above, EIS anomalies exhibit a north-south tripole in the North Pacific, with increased stability north of about $30^{\circ} \mathrm{N}$ and decreased stability south of 
a) $\partial \mathrm{LCC} / \partial \mathrm{EIS}, \triangle \mathrm{EIS}$ contours
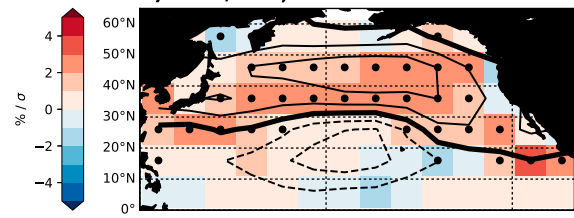

d) $\partial \mathrm{LCC} / \partial \mathrm{Tadv}, \Delta \mathrm{Tadv}$ contours
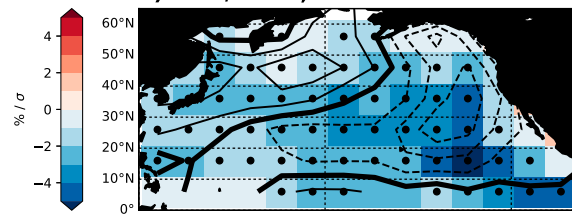

g) Actual LCC Response

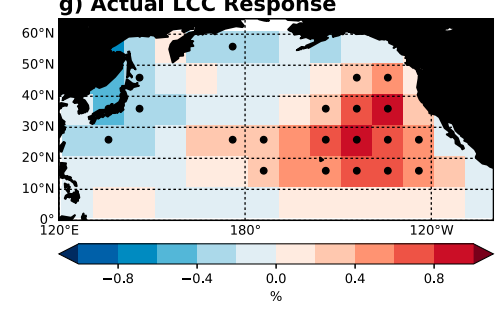

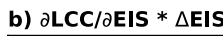

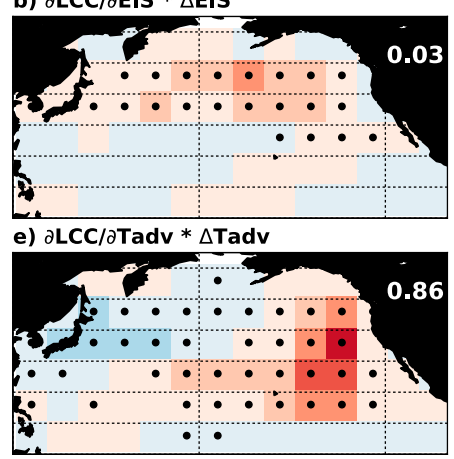

h) Sum of Contributions

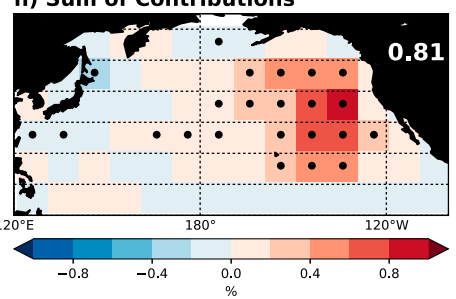

c) Variance explained by EIS
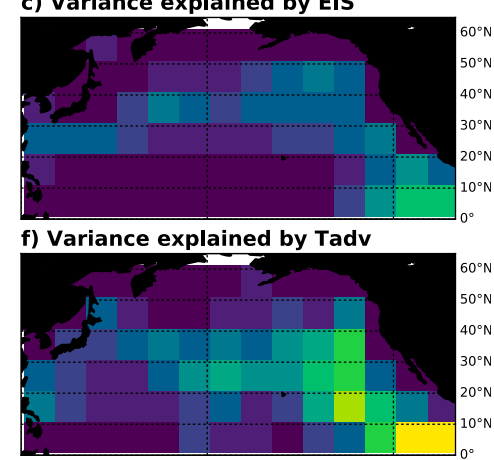

i) Variance explained by All Predictors

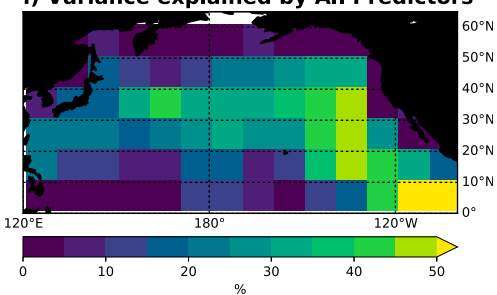

FIG. 4. Sensitivity of ISCCP low-cloud cover to a standard deviation anomaly in (a) EIS and (d) $T_{\text {adv }}$. Overlain in black contours is the actual response of each cloud-controlling factor to a $1^{\circ}$ poleward jet latitude shift, normalized by the standard deviation of the field. The contour interval is $0.05 \sigma$, with negative values enclosed by dashed contours and positive values enclosed by solid contours; the zero contour is bold. Standard deviations are computed separately for each $10^{\circ}$ box using all months over the entire ERA-Interim record. (b),(e) Product of the sensitivity of LCC to EIS and to $T_{\text {adv }}$, respectively, with the actual response of each cloud-controlling factor to a $1^{\circ}$ poleward jet shift, showing the individual contributions of each cloud-controlling factor to the change in LCC in response to a poleward jet shift predicted by the regression model. (h) The sum of these two components, which, if the model was perfect, would exactly reproduce (g) the actual LCC response to a $1^{\circ}$ poleward jet shift. Area-weighted pattern correlations between the fields shown in (b), (e), and (h) and the field shown in (g) are displayed in white font over North America. Interannual variance in LCC explained by (c) EIS, (f) $T_{\text {adv }}$, and (i) their sum. Color bars at bottom of each column apply to all panels of that column, except for (a) and (d), whose color bars are provided to their left. Black dots in the left two columns indicate values that are statistically significant at $95 \%$ confidence.

$30^{\circ} \mathrm{N}$ (Fig. 4a). The positive and negative EIS anomalies are comparable in size but the positive anomalies occur in a region in which LCC is more strongly sensitive to a standardized change in EIS. Therefore, the EIS-induced LCC increases north of $30^{\circ} \mathrm{N}$ are larger than the EIS-induced LCC decreases south of $30^{\circ} \mathrm{N}$ (Fig. 4b). The EIS-induced LCC patterns are quite different from the actual LCC anomalies in response to the jet shift (Fig. 4g), with a pattern correlation of 0.03 .

Anomalous cold advection over all but the northwestern portion of the North Pacific (Fig. 4d) induces large increases in LCC in these regions, particularly in the region between $20^{\circ}-40^{\circ} \mathrm{N}$ and $160^{\circ}-130^{\circ} \mathrm{W}$, where both the cold advection anomaly and the LCC sensitivity to cold advection are large (Fig. 4e). Decreases in LCC in the northwestern part of the domain are also attributable to increased warm advection (Fig. 4e). This pattern of LCC anomalies is highly correlated $(r=0.86)$ with the actual LCC anomalies shown in Fig. $4 \mathrm{~g}$, and indicates that the $T_{\text {adv }}$ pattern plays an important role in driving LCC anomalies in response to interannual jet shifts.
The connections observed here between the poleward-shifted jet, strengthened subtropical anticyclone, enhanced cold advection, and larger low-cloud fraction are consistent with the findings from a nearly 25-yr ship-based weather station record in the northeast Pacific at $30^{\circ} \mathrm{N}, 140^{\circ} \mathrm{W}$ (Klein et al. 1995). In that study, it was found that a stronger subtropical high favored increased low-level cloud amount at the observing station because of increased incidence and strength of cold advection and decreased incidence of midlatitude cyclones that could disrupt boundary layer processes.

The sum of both individual components of the multiple linear regression model is shown in Fig. 4h. Though imperfect, it largely reproduces the actual LCC response (Fig. 4g), both in terms of the spatial pattern $(r=0.81)$ and the magnitude of the anomalies. The same is true for all cloud datasets considered, with pattern correlations ranging from 0.69 to 0.85 across datasets (not shown). The regression model appears to better capture the increase in LCC in the eastern part of the domain than the decrease in LCC in the western part of the domain. 
Over most grid boxes of the North Pacific, more interannual variance in LCC is explained by $T_{\mathrm{adv}}$ anomalies (Fig. 4f) than by EIS anomalies (Fig. 4c). In many eastern North Pacific grid boxes, $T_{\text {adv }}$ explains more than $30 \%$ of the interannual variance in LCC. A dominant role of surface temperature advection in driving LCC variance was also found by Seethala et al. (2015) in subtropical regions. Less of the interannual variance in cloud properties is explained by these predictors in the western portion of the basin, hence the aforementioned poorer performance of the regression model there.

\section{e. Do climate models capture the observed response of clouds and meteorology to jet shifts?}

To further quantify the level of agreement between the actual cloud response and those predicted by the regression model, and to compare these quantities across observational datasets and with climate models, we compute average LCC sensitivities and responses over the red box region. For all results shown below, anomalies in the predictors and LCC are first averaged over this domain before regression slopes are computed. For both the observations and GCMs, cloud-controlling factors are first normalized by the standard deviation of the observed deseasonalized time series in the red box region. This allows the LCC sensitivities and the anomalies of the predictors to be directly compared across predictors, observational datasets, and models, as they are expressed with respect to a common $1 \sigma$ observed interannual anomaly in each of the two predictors. Unless otherwise noted, model-based results will refer to $\mathrm{LCC}_{V}$, as the sample size is larger and they generally are in close agreement with results from $\mathrm{LCC}_{C}$ and $\mathrm{LCC}_{I}$.

First, we evaluate the ability of models to capture the observed sensitivity of LCC to the two cloud-controlling factors (Fig. 5a). In agreement with observations, most models show a statistically significant increase of LCC with increasing EIS when holding $T_{\text {adv }}$ fixed (Fig. 5a, column 1). No models show a statistically significant negative relationship. However, whereas observational datasets indicate $\partial \mathrm{LCC} / \partial \mathrm{EIS}$ ranging between $0.8 \%$ and $2.0 \% \sigma^{-1}\left(1.6 \%-4.2 \% \mathrm{~K}^{-1}\right.$ increase in EIS), the majority of models exhibit smaller values, with an interquartile range (IQR) spanning $0.5 \%-1.1 \% \sigma^{-1}$ $\left(1.0 \%-2.3 \% \mathrm{~K}^{-1}\right.$ increase in EIS). This indicates that, although the models also increase LCC with increasing EIS as observed, they tend to underestimate the strength of this relationship. We also find that the majority of models underestimate the variance in LCC explained by EIS in this region (not shown). This is consistent with the results of Grise and Medeiros (2016) and Myers and Norris (2016) for midlatitude and subtropical SW CRE, respectively, and the results of Qu et al. (2014, 2015) for subtropical stratocumulus cloud fraction.

All observational datasets agree on a decrease of LCC with increases in $T_{\mathrm{adv}}$ when holding EIS fixed of about $1.0 \%-1.7 \% \sigma^{-1}\left(4.0 \%-7.0 \%\right.$ per $\mathrm{K}$ day ${ }^{-1}$; Fig. 5a, column 2). In all datasets, this decrease is statistically significant. Only 15 out of 35 models produce statistically significant relationships of the correct sign, namely, an increase in LCC with increasing cold advection. Nine models produce statistically significant relationships of the wrong sign, and 11 produce statistically insignificant relationships. Models systematically underestimate the strength of $\partial \mathrm{LCC} / \partial T_{\mathrm{adv}}$, with IQR spanning roughly $-0.3 \%$ to $0.3 \% \sigma^{-1}(-1.1 \%$ to $1.0 \%$ per $\mathrm{Kday}^{-1}$ ). In addition, we find that the vast majority of models underestimate the variance in LCC explained by $T_{\mathrm{adv}}$, even more so than is the case for EIS (not shown). This is consistent with results for subtropical stratocumulus regions (Myers and Norris 2016). As noted earlier, this particular sensitivity is crucially important for driving the observed response of low clouds to jet shifts.

We now turn to the response of these three cloudcontrolling factors to a $1^{\circ}$ poleward jet shift (Fig. 5b). Multiple observational estimates of the meteorological response are provided, differing only because the period of analysis varies with the satellite dataset. Whereas the sensitivity of LCC to EIS and $T_{\text {adv }}$ are of comparable magnitude but opposite sign (Fig. 5a), the response of $T_{\mathrm{adv}}$ to a jet shift is larger in magnitude than that of EIS in all time periods $\left(\Delta T_{\mathrm{adv}}\right.$ ranges from $-0.15 \sigma$ to $-0.23 \sigma$ whereas $\Delta$ EIS ranges from $0.07 \sigma$ to $0.14 \sigma$; Fig. $5 b$ ). All models simulate a statistically significant increase in both EIS and cold advection of the correct magnitude in this region (Fig. 5b). The range of observed responses of both EIS and $T_{\text {adv }}$ falls within the IQR of model values. Increases in cold advection in this region are almost entirely driven by anomalously northerly winds rather than by SST gradient anomalies (not shown).

Box-mean $\Delta \mathrm{LCC}$ contributions from $\Delta \mathrm{EIS}$ and $\Delta T_{\mathrm{adv}}$ are shown in Fig. $5 c$, and are scattered against each other in Fig. 6. In general the models produce an increase in LCC due to EIS increases in response to a poleward jet shift, in agreement with observations (Fig. 5c, column 1). However, because they underestimate $\partial \mathrm{LCC} / \partial \mathrm{EIS}$, most models underestimate the EIS-driven increase in LCC, in qualitative agreement with Grise and Medeiros (2016). Whereas observations indicate an $0.08 \%-0.21 \%$ increase in LCC due to EIS increases, models indicate very small increases from this component falling in a very narrow range (IQR of $0.04 \%-0.10 \%$ ), with only the largest model values comparable to observed values. 
a) Sensitivity of LCC to Cloud Controlling Factors

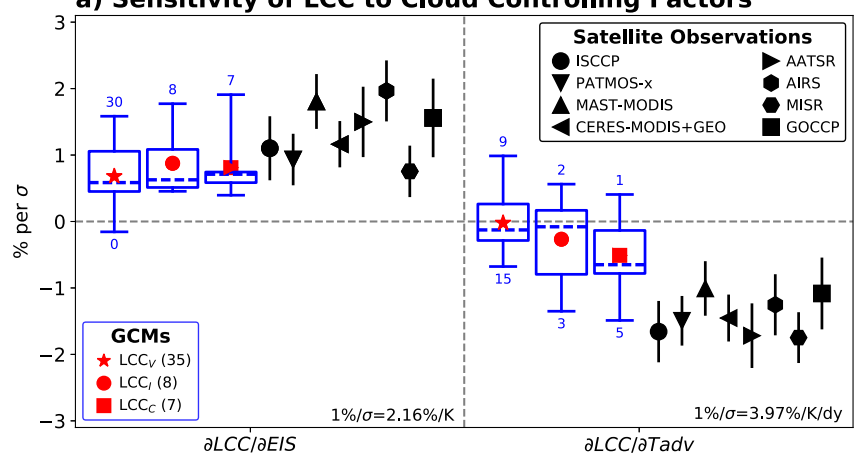

b) Response of Cloud Controlling Factors

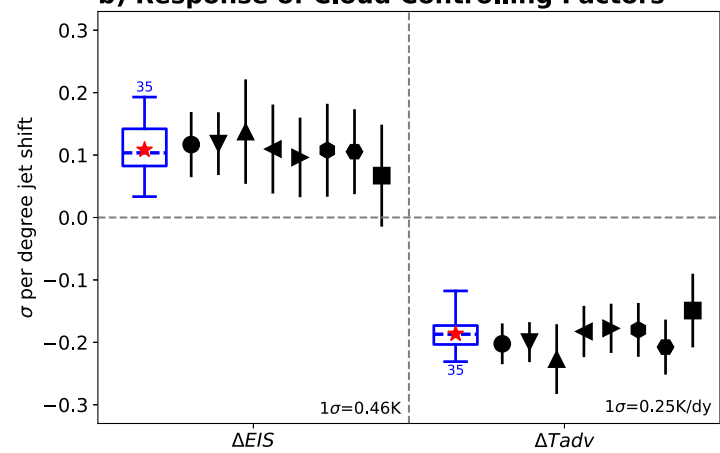

c) $\triangle$ LCC due to Individual Cloud Controlling Factors

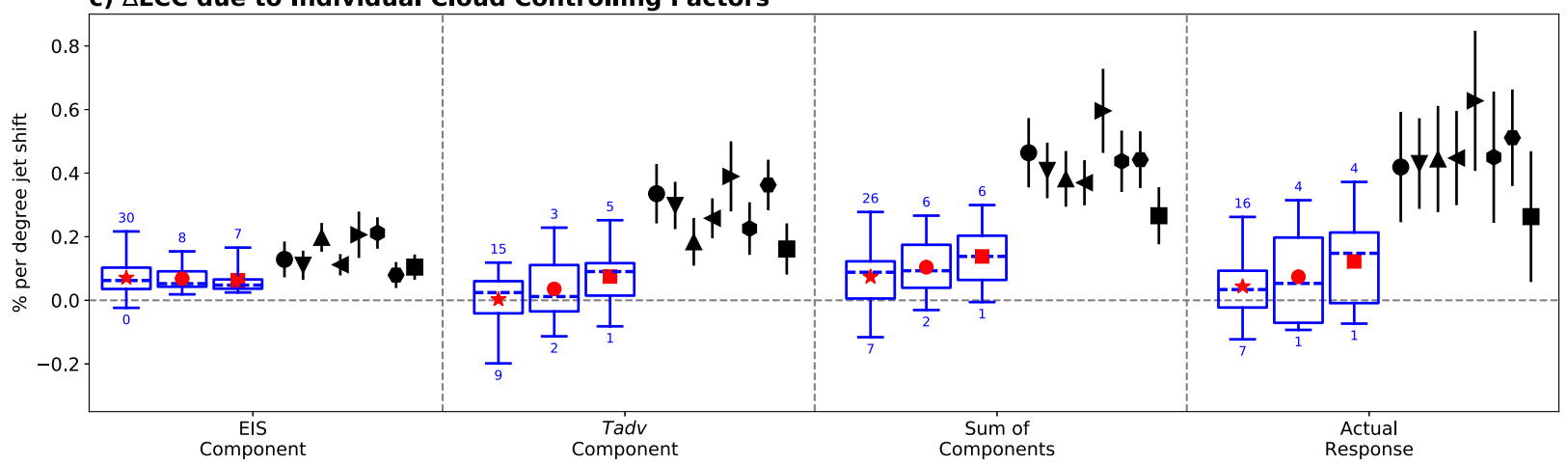

FIG. 5. Quantities averaged over the red box region of the North Pacific, for both the piControl runs of 35 GCMs and eight satellite datasets. GCM results are summarized in the box-and-whisker plots, in which whiskers extend from the minimum to the maximum, the box extends from the 25 th to 75 th percentile, the dashed blue line represents the median, and the red symbol represents the mean. Three boxes are provided in (a) and (c), for results derived using three estimates of LCC (star: $\mathrm{LCC}_{V}$, circle: $\mathrm{LCC}_{I}$, and triangle: $\mathrm{LCC}_{C}$ ). Values printed above and below the whiskers indicate the number of models for which the plotted quantity is greater or less than zero at $95 \%$ confidence. The total number of models providing a given quantity is shown in the legend. (a) Sensitivity of LCC to a $1 \sigma$ anomaly in EIS and $T_{\text {adv }}$. Observational error bars represent the $95 \%$ confidence intervals on the regression coefficients. The LCC sensitivity to a $1 \sigma$ anomaly expressed in physical units is displayed in each column. (b) Response of each cloud-controlling factor to a $1^{\circ}$ poleward jet shift, normalized by the observed standard deviation of the field within the red box region. Observational values vary with satellite dataset because they are computed using meteorological data during the period of overlap with the satellite. Observational error bars represent the $95 \%$ confidence intervals. The size of a $1 \sigma$ anomaly expressed in physical units is displayed in each column. (c) Product of quantities in (a) and (b), their sum, and the actual responses. Observational error bars for individual components represent the LCC sensitivity uncertainty from (a) only. Observational error bars for the sum of components are computed by summing component errors in quadrature. Observational error bars for the actual response represent the $2 \sigma$ uncertainty.

As discussed previously, the cold advection-driven increase in LCC is the largest contributor to observed LCC increases in this region (Fig. 5c, column 2). In all but three observational datasets (AIRS, MASTMODIS, and GOCCP), the $T_{\mathrm{adv}}$-driven component is statistically significantly larger than the EIS-driven component (Fig. 6). In contrast, the EIS-driven component is larger than the $T_{\mathrm{adv}}$-driven component in nearly all models, and none of the models simulate a $T_{\text {adv }}$-driven component of the observed magnitude (Figs. 5c and 6). Namely, anomalous cold advection causes LCC increases of about $0.16 \%-0.39 \%$ in observations, whereas model $T_{\mathrm{adv}}$-driven LCC anomalies range from $-0.04 \%$ to $0.06 \%$ (IQR). Only 15 out of 35 models have a statistically significant increase in LCC from this component, with anomalous cold advection actually causing a statistically significant decrease in LCC in nine models. This error is due solely to model biases in the sensitivity of LCC to $T_{\text {adv }}$ (Fig. 5a, column 2), not their responses of $T_{\text {adv }}$ to a poleward jet shift, which are in excellent agreement with observations (Fig. 5b, column 2). Although the EIS-driven component is larger than the $T_{\mathrm{adv}}$-driven component in nearly all models, we find that the intermodel variance in the sensitivity of LCC to $T_{\text {adv }}$ is the dominant source of intermodel spread in the LCC response in this region, accounting for over $60 \%$ of the variance (not shown).

Further evidence that GCMs capture the observed large-scale meteorological responses with much greater fidelity than they capture the cloud and radiation 


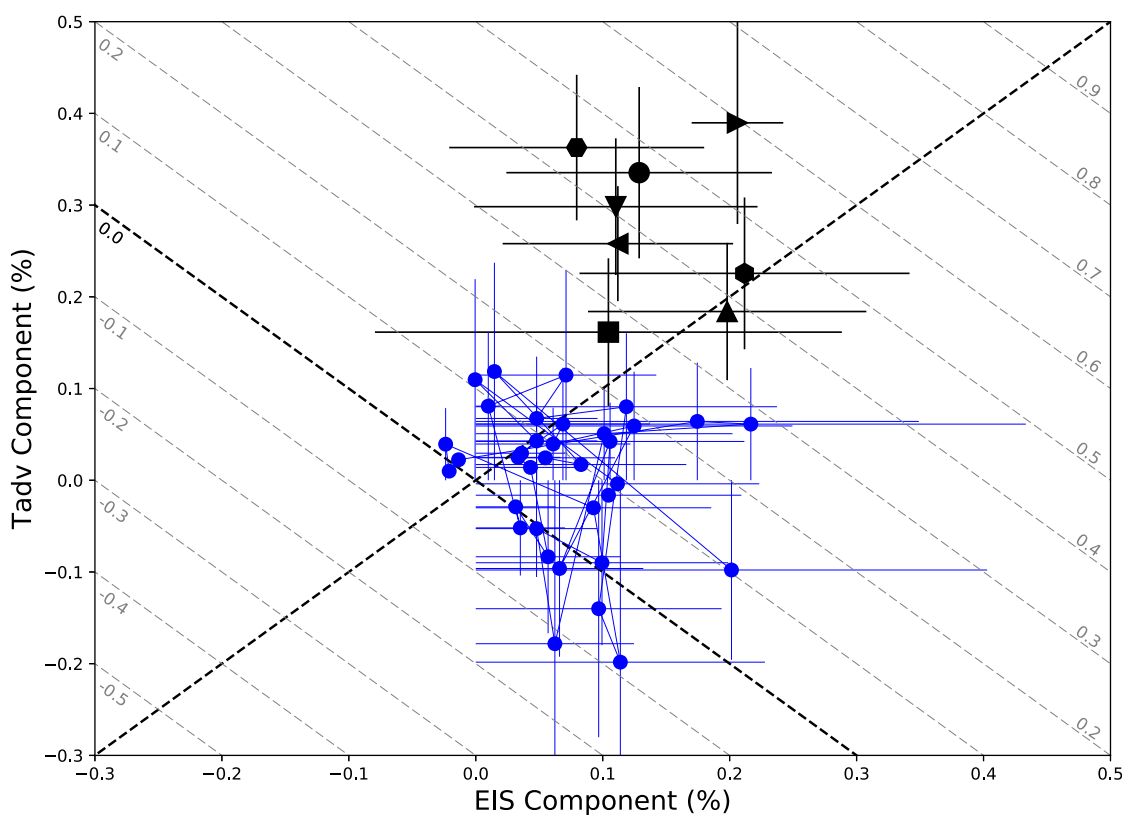

FIG. 6. LCC anomalies attributable to EIS anomalies plotted against those attributable to $T_{\text {adv }}$ anomalies in the red box region, for both models (blue symbols) and observations (black symbols). Observational cloud datasets are indicated with the same symbols as in Fig. 5. Error bars represent the $95 \%$ confidence intervals. Lines of constant total predicted $\Delta \mathrm{LCC}$ are indicated.

responses is provided in Fig. 7. These so-called Taylor diagrams (Taylor 2001) indicate that most models' meteorological responses have pattern correlations with the observed responses exceeding 0.6 , whereas most models' net CRE and LCC responses have pattern correlations well below 0.5 . The spatial variance of the multimodel mean EIS and $T_{\text {adv }}$ responses are in very close agreement with observed responses, though most models overestimate the spatial variance of the $T_{\mathrm{adv}}$ response (Figs. 7a,b). As a rough measure of observational uncertainty related to dataset and time period, the ISCCP-FD net CRE responses are also shown in Fig. 7c. These have nearly the same spatial variance as those from CERES, and are correlated at nearly 0.8 , much larger than any models.

Consistent with the model biases in net CRE, models systematically underestimate the spatial variance of observed ISCCP LCC anomalies and have very small pattern correlations with them (Fig. 7d). Similar results are seen for the $\mathrm{LCC}_{I}$ fields in models implementing COSP (not shown). Qualitatively, these results are also unchanged if we recompute all statistics over the period September 2002-December 2009 when all cloud datasets but CALIPSO-GOCCP are fully available (not shown). The differences between models and ISCCP exceed the differences among the observational datasets, except for the CALIPSO-GOCCP dataset, which has much larger spatial variance than ISCCP and is as poorly correlated with ISCCP as a typical model.

In summary, we conclude that GCMs systematically underestimate the LCC increase in this region in response to a poleward jet shift because they underestimate contributions from increases in cold advection and, to a lesser extent, EIS. Because the models generally closely capture the observed responses of EIS and $T_{\text {adv }}$ to jet shifts, their underestimates of LCC increases arise solely from LCC lacking sufficient sensitivity to EIS and, more importantly, $T_{\text {adv }}$. Such biases in the sensitivity of low clouds to their environment are likely strongly governed by subgrid-scale (parameterized) processes (Qu et al. 2014; Geoffroy et al. 2017; Cesana et al. 2017). Finally, we note that the sum of individual components closely reproduces the actual LCC responses in this region in both observations and, to a lesser extent, models, validating the regression model (Fig. 8).

\section{Conclusions and discussion}

Poleward jet shifts associated with interannual climate variability result in negligible net cloud radiative effects averaged over the North Pacific basin. In stark contrast to what would be expected if the total cloud field shifted poleward along with the jet toward regions of reduced 
Modeled vs Observed Responses to Jet Shift
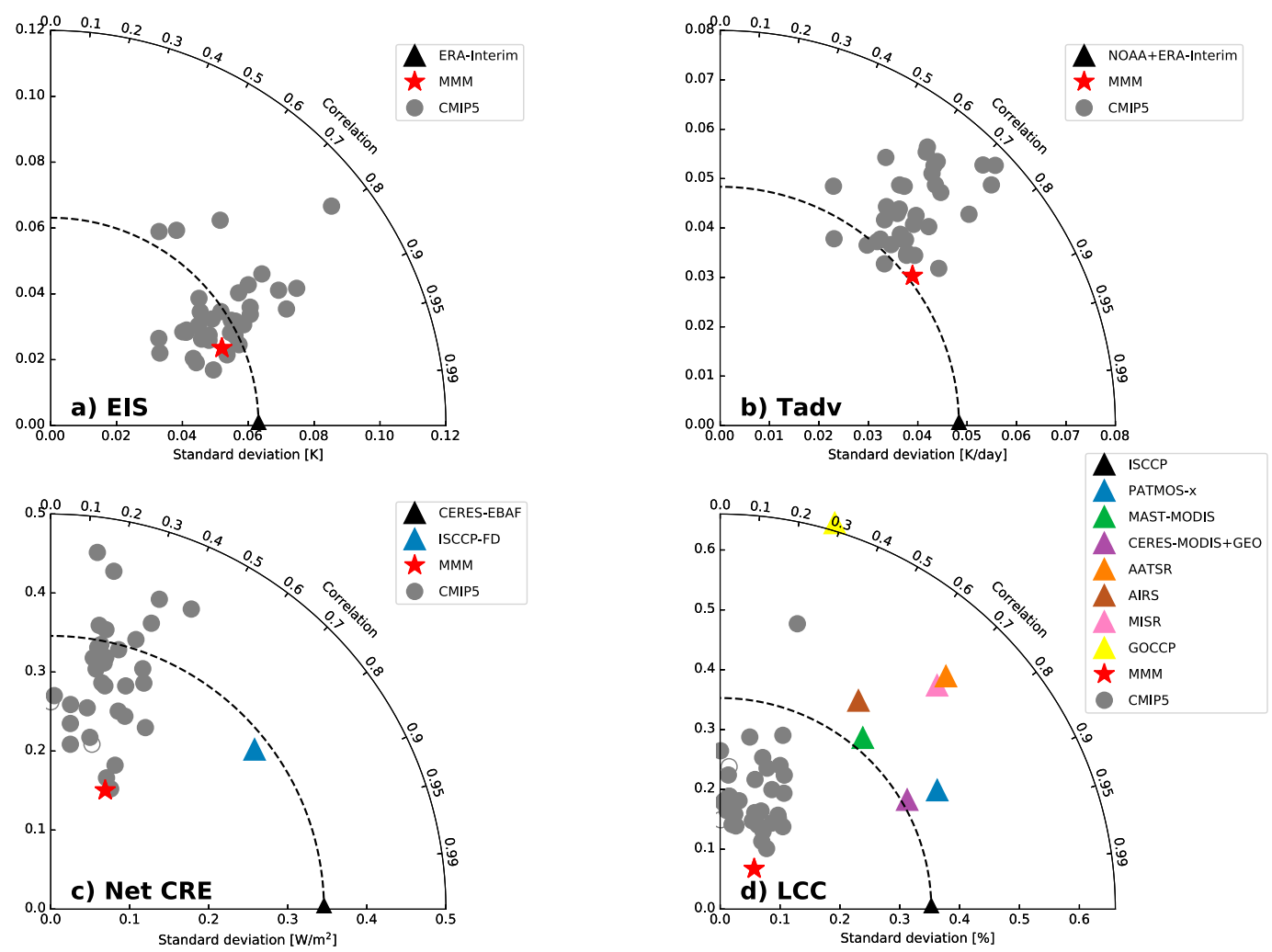

FIG. 7. Taylor diagram comparing modeled and observed responses of (a) EIS, (b) $T_{\text {adv }}$, (c) net CRE, and (d) LCC to a $1^{\circ}$ poleward jet shift in the North Pacific basin $\left(0^{\circ}-65^{\circ} \mathrm{N}, 120^{\circ} \mathrm{E}-90^{\circ} \mathrm{W}\right)$. The radial distance from the origin denotes the spatial standard deviation of each dataset, with the dashed line passing through the spatial standard deviation of the reference observational dataset (shown as a black triangle). The angular distance from the horizontal denotes the spatial pattern correlation coefficient between each dataset and the observational dataset. Individual CMIP5 models are shown in gray dots. The multimodel mean is shown as a red star. An alternative observational dataset of net CRE (from ISCCP-FD) is also shown as a blue triangle in (c). Modeled $\mathrm{LCC}_{V}$ values are shown in (d), along with LCC values from all satellite datasets. To visualize some models that would otherwise lie outside of the plot domain, fields that are negatively correlated with the reference observation are plotted as unfilled symbols, with their sign reversed. For all but the unfilled symbols, the distance to the black triangle indicates the centered RMS error.

insolation, observed jet shifts are characterized by zonally asymmetric net CRE anomalies, with cloud-induced cooling in the southeastern part of the basin countered by cloud-induced warming to the northwest. These CRE anomalies are primarily caused by anomalies in the coverage of low-level clouds. Specifically, low clouds dramatically increase over a broad expanse of the eastern subtropical and midlatitude North Pacific when the jet is anomalously poleward. These low-cloud-cover anomalies are robust across eight satellite datasets that span different time periods and are derived using diverse retrieval algorithms applied to measurements from both active and passive sensors across a range of spectral channels aboard both polar-orbiting and geostationary satellites.

We find that the low-cloud increases are primarily caused by enhanced cold advection in the eastern Pacific set up by anomalous northerly winds associated with an anomalous anticyclonic circulation spanning the Pacific basin. Increases in low-cloud cover are favored by enhanced cold advection because it drives enhanced turbulent fluxes from the ocean into the boundary layer as relatively cold and dry air flows southward over relatively warmer water. Increases in EIS play a secondary role in increasing low-cloud coverage. Models closely capture the large-scale dynamical response of the atmosphere to interannual variations in jet latitude, but the sensitivity of models' LCC to cold advection is systematically too weak, leading to a systematic underestimate of the LCC increase. These biases are likely caused by parameterized physics in the models and may also be relevant to the representation of cloud feedbacks in GCMs under global warming. However, the 


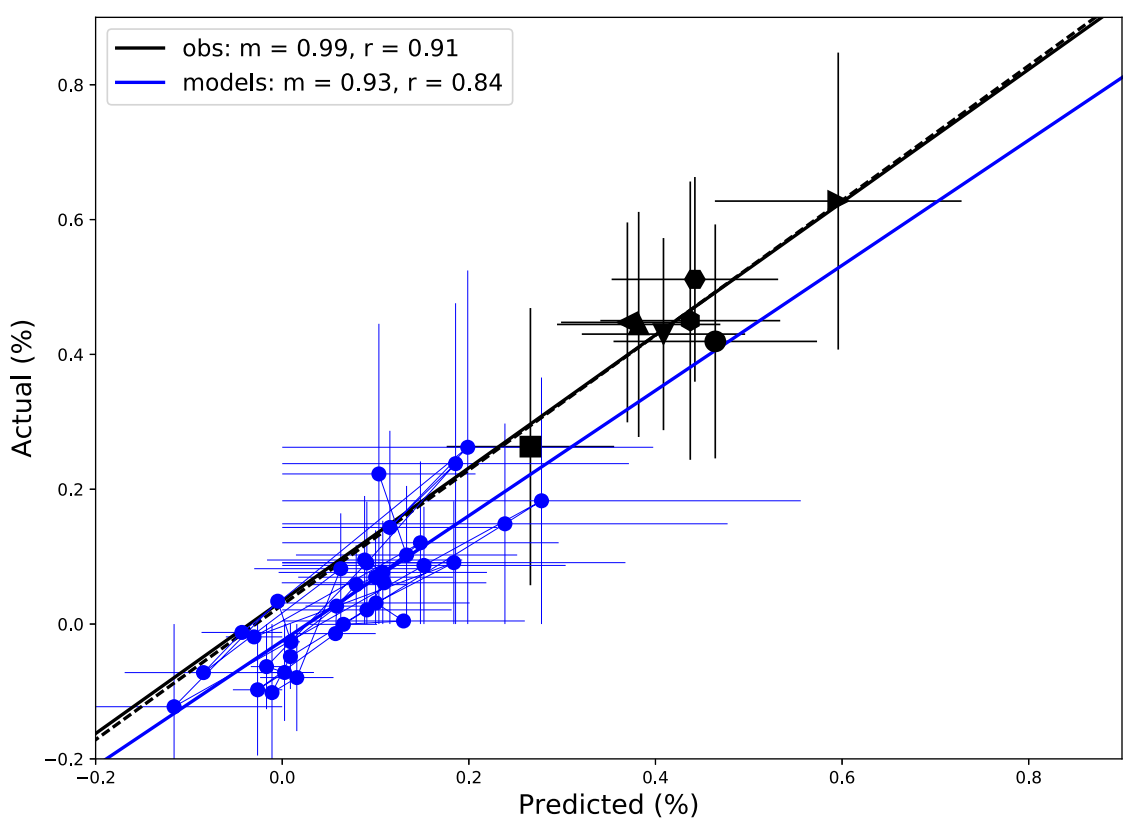

FIG. 8. Actual LCC anomalies in the red box region plotted against LCC anomalies predicted by the multilinear regression model, for both models (blue symbols) and observations (black symbols). Observational cloud datasets are indicated with the same symbols as in Fig. 5. Error bars represent the $95 \%$ confidence intervals.

component of the global warming response of low clouds attributable to $T_{\text {adv }}$-based upon the observed sensitivity of clouds to $T_{\text {adv }}$ and GCM predictions of how much $T_{\text {adv }}$ changes with global warming-has been shown to be much smaller than either the SST or EIS components, at least in the subtropics (Qu et al. 2015; Myers and Norris 2016). Thus, this GCM bias is likely to play a bigger role for internal variability of the climate system than for long-term cloud feedbacks.

Our results lead to an apparently different conclusion than those of Grise and Medeiros (2016), who highlighted the roles of EIS and $\omega_{500}$ in governing the cloud-radiative response to jet shifts. This can partly be reconciled by noting that Grise and Medeiros (2016) sought to understand the responses of the individual SW and LW CRE components and of high-, low-, and total cloud cover. In contrast, we sought to understand the responses of low clouds that are better tied to net CRE anomalies than to either the LW or SW components. Had we considered high-cloud cover in our analysis, it would have been necessary to include $\omega_{500}$ as one of our predictors. Nevertheless, to optimally explain low-cloudcover anomalies based on their environmental controlling factors, $T_{\text {adv }}$ rather than $\omega_{500}$ must be considered in addition to EIS.

In this study we have focused on the response of clouds to the jet location over the North Pacific Ocean in all months of the year, mainly to maximize the sample size. One can imagine that the results may vary with season and may be different in other ocean basins. The results shown in this study do not qualitatively change if the DJF season is considered in isolation, as that is the season with the largest increases in eastern North Pacific low-cloud cover and the one that apparently dominates the full response using all months (Fig. 10 of Grise and Medeiros 2016). LCC responses computed for the JJA season in isolation are much smaller in magnitude and less spatially coherent than shown in Fig. 2, and the meteorological responses are considerably less dramatic than those shown in Fig. 3 (not shown). Maps of the sensitivity of LCC to EIS and $T_{\text {adv }}$, and maps of the EISand $T_{\mathrm{adv}}$-driven $\triangle \mathrm{LCC}$ components are nearly the same for DJF as they are for all months, except both the LCC sensitivities and the responses of cloud-controlling factors have larger magnitude in DJF (not shown). Over the Southern Ocean and North Atlantic basins, we find that surface cold advection plays a similarly dominant role in inducing regions of enhanced low-cloud coverage as in the North Pacific, albeit with a slightly larger role for EIS than was found in the North Pacific (not shown). This will be explored further in a subsequent study.

One may also expect midlatitude clouds to respond differently to changes in jet strength, frequency or strength of midlatitude cyclones, and shifts of the Hadley cell edge. Indeed, Tselioudis et al. (2016) argue that poleward shifts in the Hadley cell edge are the more 
important driver of midlatitude radiative feedbacks than poleward jet shifts because they are in general more effective at inducing poleward cloud shifts and clearing out the subtropics. How and why shifts of the Hadley cell edge affect low clouds differently and independently from concurrent poleward jet shifts remains to be understood, and would benefit from considering the responses of cloud-controlling factors. This is especially poignant given the apparent dependence of clouds, radiation, and even climate sensitivity on the location of the Hadley cell edge in GCMs (Lipat et al. 2017).

As noted in the introduction, observational analyses using long-term satellite and ground-based cloud observations indicate decreasing midlatitude cloud-cover trends, especially on the equatorward side of the climatological jet (Bender et al. 2012; Eastman and Warren 2013; Marvel et al. 2015; Norris et al. 2016). These studies commonly attribute these cloud trends to poleward circulation shifts without explicitly establishing the linkages between cloud properties and largescale dynamics. Assuming the observational trends are real, then they need to be reconciled with the increasing evidence that poleward jet shifts are not responsible for reductions in total cloud cover at midlatitudes. Interpreting cloud changes through the lens of how their thermodynamic controls are changing seems to be a more useful approach than assessing their relatively indirect dependence on features of the large-scale circulation.

Because our study was motivated by a potential jet shift-induced cloud feedback and its possible implications for climate sensitivity, we have focused solely on understanding the impact of jet shift-induced low-cloud responses on top-of-the-atmosphere net radiation. Having confirmed previous findings that cloud responses to interannual jet shifts result in negligible perturbations to the planetary energy balance, it remains an open question how the very substantial regional cloud anomalies-including midlevel- and high-cloud anomalies that were not discussed here-may induce gradients in surface radiation and atmospheric radiative cooling, thereby affecting baroclinicity and potentially feeding back on jet strength and/or location. Observational analyses are needed to complement the growing body of GCM-based inferences on this topic (Ceppi et al. 2012, 2014; Li et al. 2015; Voigt and Shaw 2015; Ceppi and Hartmann 2016), especially in light of the model response errors highlighted in this study.

Acknowledgments. The work of M.D.Z., S.A.K., C.Z., and A.M.D. was supported by the Regional and Global Climate Modeling Program of the Office of Science of the U.S. Department of Energy (DOE) and was performed under the auspices of the U.S. DOE by LLNL under contract DE-AC52-07NA27344. M.D.Z.'s work was additionally supported by the NASA New Investigator Program (NNH14AX83I). K.M.G. was supported by the National Science Foundation under Grant AGS-1522829. M.W.C. was supported by the European Space Agency Climate Change Initiative Cloud_cci (contract 4000109870/13/I-NB). We acknowledge the World Climate Research Programme's Working Group on Coupled Modelling, which is responsible for CMIP, and we thank the climate modeling groups (listed in Table 2) for producing and making available their model output. For CMIP, the U.S. DOE's Program for Climate Model Diagnosis and Intercomparison provided coordinating support and led development of software infrastructure in partnership with the Global Organization for Earth System Science Portals. We thank Tim Myers, Bernard Lipat, and three anonymous reviewers for their helpful comments. CERES-EBAF Ed4.0 and CldTypHist data were obtained from the NASA Langley Research Center CERES ordering tool at http:// ceres.larc.nasa.gov. ISCCP-FD data were obtained from the NASA Goddard Institute for Space Studies (http:// isccp.giss.nasa.gov/projects/flux.html). The NOAA Optimum Interpolation (OI) SST dataset is provided by NOAA/NCEI at https://www.ncdc.noaa.gov/oisst. National Oceanography Centre/University of Southampton (NOCS) Surface Flux Dataset v2.0 is provided by the Research Data Archive at the National Center for Atmospheric Research, Computational and Information Systems Laboratory at http://rda.ucar.edu/ datasets/ds260.3/. ICOADS data are provided by the NOAA/OAR/ESRL/PSD, Boulder, Colorado, from their website at http://www.esrl.noaa.gov/psd/. ERAInterim data are provided by ECMWF at http://apps. ecmwf.int/datasets/data/interim-full-daily/levtype $=\mathrm{sfc} /$. ISCCP-D1 data are available from https://eosweb.larc. nasa.gov/project/isccp/isccp_d1_table. PATMOS-x data are available from the GEWEX cloud assessment at http://climserv.ipsl.polytechnique.fr/gewexca/instruments/ PATMOSX.html. MODIS Collection 6 data are accessible from https://modis-atmos.gsfc.nasa.gov/MOD06_ L2/index.html. We thank Dr. Q. Yue for advice on the appropriate MODIS dataset. AATSR data are available from the Centre for Environmental Data Analysis (CEDA; http://www.ceda.ac.uk, ESA, 2014). AIRS data are provided by the NASA Goddard Earth Sciences Data Information and Services Center (GESDISC) at https://disc.gsfc.nasa.gov/. MISR data are available from http://climserv.ipsl.polytechnique.fr/cfmip-obs/. CALIPSOGOCCP data are provided at http://climserv.ipsl. polytechnique.fr/cfmip-obs/. 
Cloud-Induced Net TOA Radiation Anomalies in Response to Jet Shift
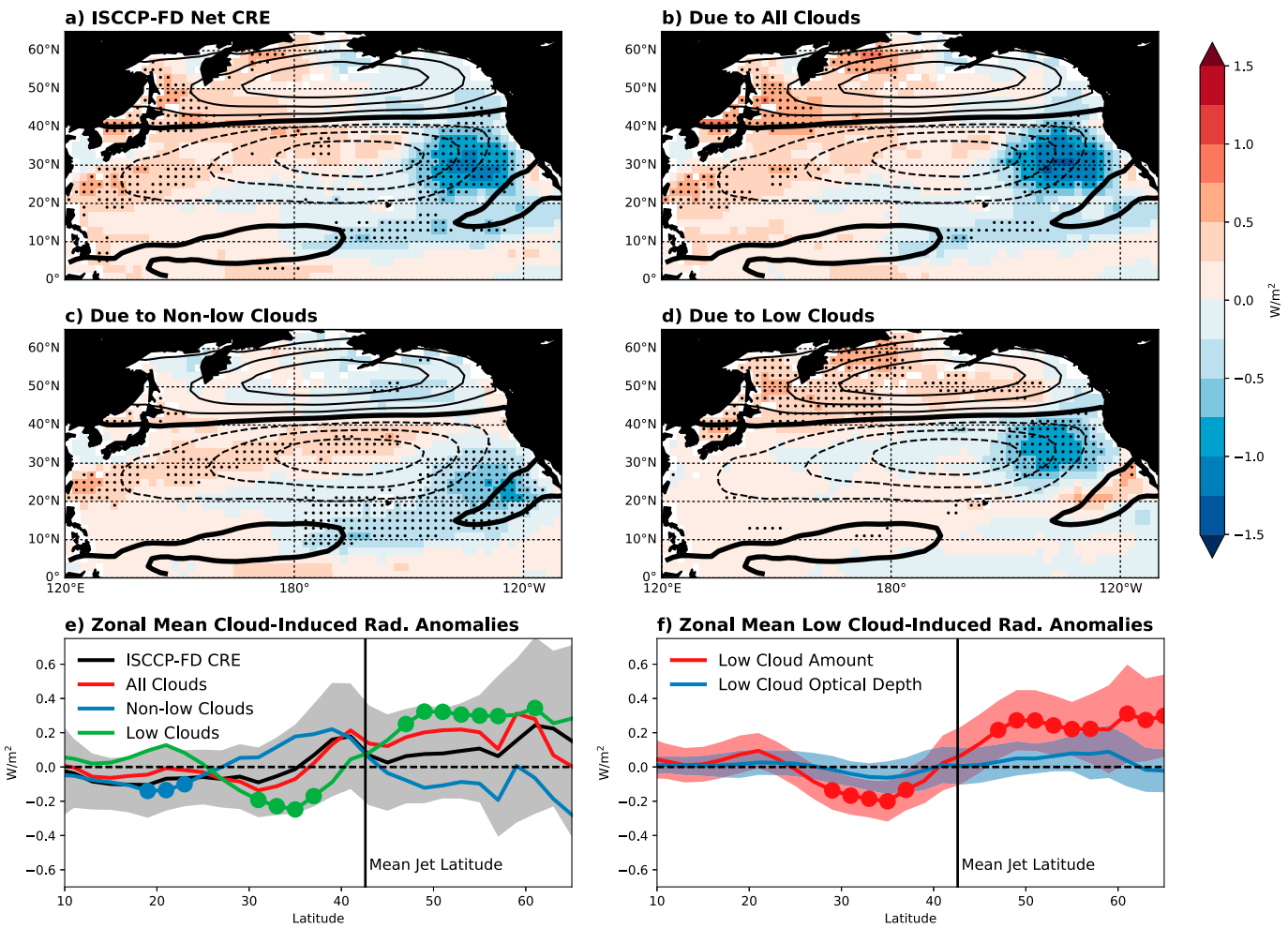

FIG. A1. As in Fig. 1, but for (a) ISCCP-FD net CRE anomalies and TOA net radiation induced by (b) all clouds, (c) nonlow clouds, and (d) low clouds in response to a $1^{\circ}$ poleward jet shift. Anomalies in (b)-(d) are derived using cloud radiative kernels and ISCCP cloud fraction histogram anomalies.

\section{APPENDIX A}

\section{Consistency of TOA Radiation Anomalies among Datasets}

As a check on the net CRE anomalies and attribution to individual cloud types shown in Fig. 1 with independent datasets, we show in Fig. A1 the net CRE anomalies in response to a $1^{\circ}$ jet shift derived from ISCCP-FD fluxes, along with the TOA net radiation anomalies induced by all clouds (Fig. Alb), nonlow clouds (Fig. A1c), and low clouds (Fig. A1d) derived using cloud radiative kernels applied to anomalous ISCCP cloud fraction histograms. The longer ISCCP dataset used in generating this figure allows for more robust statistics and results in smoother fields with anomalies of smaller amplitude than those shown in Fig. 1. However, the qualitative picture remains unchanged: A $1^{\circ}$ poleward jet shift induces a northwest-tosoutheast dipole in the net CRE anomalies (Fig. A1a) that is confirmed in the kernel calculation (Fig. A1b), with large negative anomalies in the southeast Pacific that are primarily caused by increases in low-cloud coverage rather than optical depth (Figs. A1d,f).
Unlike in Figs. 1c and 1d, however, the region of dominant nonlow cloud contribution extends more broadly from $10^{\circ}$ to $25^{\circ} \mathrm{N}$ between $180^{\circ}$ and $120^{\circ} \mathrm{W}$, and from $20^{\circ}$ to $40^{\circ} \mathrm{N}$ between $120^{\circ} \mathrm{E}$ and $150^{\circ} \mathrm{W}$ (Figs. A1c,d). Unlike Fig. 1e, the zonal-mean ISCCP-FD net CRE anomalies are not statistically different from zero at any latitude (Fig. A1e). These quantitative differences persist if considering only the period September 2002-December 2009, when ISCCP, CERES, and MODIS datasets overlap, indicating that they are due to differences in the observational datasets rather than to different time periods sampled (not shown).

\section{APPENDIX B}

\section{Choosing the Optimum Set of Predictors}

We assess the variance in LCC in the northeast Pacific red box region $\left(20^{\circ}-50^{\circ} \mathrm{N}, 180^{\circ}-120^{\circ} \mathrm{W}\right)$ explained by two- and three-variate regression models for all possible combinations of 10 predictors that are common in the low-cloud literature. Specifically, in addition to $T_{\mathrm{adv}}$ and EIS, which are discussed in the main text, we consider the following factors used in Qu et al. (2015): surface wind 
speed $\left(U_{S}\right)$, pressure vertical velocity at $700 \mathrm{hPa}\left(\omega_{700}\right)$, sea surface temperature (SST), the specific humidity difference between 1000 and $700 \mathrm{hPa}(\delta q)$, and the vertical-mean relative humidity from 700 to $300 \mathrm{hPa}$ (RHtrop). We also consider relative humidity at $700 \mathrm{hPa}$ $\left(\mathrm{RH}_{700}\right)$, which was used in Myers and Norris (2016), $T_{700}$, which was used in Seethala et al. (2015), and surface buoyancy flux (BF), which is a linear combination of surface sensible and latent heat fluxes (Randall 1987).

We find that the best possible two-variable model (which employs EIS and $T_{\text {adv }}$ ) explains $49 \%$ of the LCC variance on average across the satellite datasets, while the best possible three-variate model (which employs EIS, $T_{\text {adv }}$, and RHtrop) explains $52 \%$ of the variance (not shown). The spatial pattern correlation between predicted and actual LCC anomalies in response to a poleward jet shift degrades only slightly if using a model with only EIS and $T_{\mathrm{adv}}$ as predictors rather than one that additionally includes RHtrop (e.g., from 0.85 to 0.81 for ISCCP). This is true for all eight satellite cloud datasets (not shown).

Despite explaining marginally more LCC variance by including RHtrop, there is a risk that including such a predictor will degrade the model's skill when applied to independent data. Based on the desire to minimize the number of predictors while maximizing regression model skill, we decided to use only EIS and $T_{\text {adv }}$ as predictors. For predicting the response of low-cloud cover to other changes such as global warming, one would likely need to include additional predictors (most notably, SST).

\section{REFERENCES}

Aumann, H. H., and Coauthors, 2003: AIRS/AMSU/HSB on the Aqua mission: Design, science objectives, data products, and processing systems. IEEE Trans. Geosci. Remote Sens., 41, 253-264, https://doi.org/10.1109/TGRS.2002.808356.

Barnes, E. A., and L. Polvani, 2013: Response of the midlatitude jets, and of their variability, to increased greenhouse gases in the CMIP5 models. J. Climate, 26, 7117-7135, https://doi.org/ 10.1175/JCLI-D-12-00536.1.

Baum, B. A., W. P. Menzel, R. A. Frey, D. C. Tobin, R. E. Holz, S. A. Ackerman, A. K. Heidinger, and P. Yang, 2012: MODIS cloud-top property refinements for Collection 6. J. Appl. Meteor. Climatol., 51, 1145-1163, https://doi.org/10.1175/ JAMC-D-11-0203.1.

Bender, F. A. M., V. Ramanathan, and G. Tselioudis, 2012: Changes in extratropical storm track cloudiness 1983-2008: Observational support for a poleward shift. Climate Dyn., 38, 2037-2053, https://doi.org/10.1007/s00382-011-1065-6.

Berry, D. I., and E. C. Kent, 2009: A new air-sea interaction gridded dataset from ICOADS with uncertainty estimates. Bull. Amer. Meteor. Soc., 90, 645-656, https://doi.org/10.1175/ 2008bams2639.1.

- , and - 2011: Air-sea fluxes from ICOADS: The construction of a new gridded dataset with uncertainty estimates. Int. J. Climatol., 31, 987-1001, https://doi.org/10.1002/joc.2059.
Bodas-Salcedo, A., and Coauthors, 2011: COSP: Satellite simulation software for model assessment. Bull. Amer. Meteor. Soc., 92, 1023-1043, https://doi.org/10.1175/2011BAMS2856.1.

Bony, S., and Coauthors, 2006: How well do we understand and evaluate climate change feedback processes? J. Climate, 19, 3445-3482, https://doi.org/10.1175/JCLI3819.1.

Boucher, O., and Coauthors, 2013: Clouds and aerosols. Climate Change 2013: The Physical Science Basis, T. F. Stocker et al., Eds., Cambridge University Press, 571-657.

Bretherton, C. S., M. Widmann, V. P. Dymnikov, J. M. Wallace, and I. Blade, 1999: The effective number of spatial degrees of freedom of a time-varying field. J. Climate, 12, 1990-2009, https:// doi.org/10.1175/1520-0442(1999)012<1990:TENOSD>2.0.CO;2.

Brummer, B., 1996: Boundary-layer modification in wintertime cold-air outbreaks from the Arctic sea ice. Bound.-Layer Meteor., 80, 109-125, https://doi.org/10.1007/BF00119014.

Bunker, A. F., 1960: Heat and water-vapor fluxes in air flowing southward over the western North Atlantic Ocean. J. Meteor., 17, 52-63., https://doi.org/10.1175/1520-0469(1960)017<0052: HAWVFI $>2.0 . \mathrm{CO} ; 2$.

Ceppi, P., and D. L. Hartmann, 2015: Connections between clouds, radiation, and midlatitude dynamics: A review. Curr. Climate Change Rep., 1, 94-102, https://doi.org/10.1007/s40641-015-0010-x. , and — 2016: Clouds and the atmospheric circulation response to warming. J. Climate, 29, 783-799, https://doi.org/ 10.1175/JCLI-D-15-0394.1.

— , Y.-T. Hwang, D. M. W. Frierson, and D. L. Hartmann, 2012: Southern Hemisphere jet latitude biases in CMIP5 models linked to shortwave cloud forcing. Geophys. Res. Lett., 39, L19708, https://doi.org/10.1029/2012GL053115.

_ M. D. Zelinka, and D. L. Hartmann, 2014: The response of the Southern Hemispheric eddy-driven jet to future changes in shortwave radiation in CMIP5. Geophys. Res. Lett., 41, 3244 3250, https://doi.org/10.1002/2014GL060043.

, D. T. McCoy, and D. L. Hartmann, 2016: Observational evidence for a negative shortwave cloud feedback in middle to high latitudes. Geophys. Res. Lett., 43, 1331-1339, https://doi.org/ 10.1002/2015GL067499.

Cesana, G., K. Suselj, and F. Brient, 2017: On the dependence of cloud feedbacks on physical parameterizations in WRF aquaplanet simulations. Geophys. Res. Lett., 44, 10 762-10771, https:// doi.org/10.1002/2017GL074820.

Chahine, M. T., and Coauthors, 2006: AIRS: Improving weather forecasting and providing new data on greenhouse gases. Bull. Amer. Meteor. Soc., 87, 911-926, https://doi.org/10.1175/ bams-87-7-911.

Charlock, T. P., and V. Ramanathan, 1985: The albedo field and cloud radiative forcing produced by a general circulation model with internally generated cloud optics. J. Atmos. Sci. 42, 1408-1429, https://doi.org/10.1175/1520-0469(1985)042<1408: TAFACR $>2.0 . \mathrm{CO} ; 2$.

Chepfer, H., S. Bony, D. Winker, M. Chiriaco, J. L. Dufresne, and G. Sèze, 2008: Use of CALIPSO lidar observations to evaluate the cloudiness simulated by a climate model. Geophys. Res. Lett., 35, L15704, https://doi.org/10.1029/2008GL034207.

,,-- , G. Cesana, J. L. Dufresne, P. Minnis, C. J. Stubenrauch, and S. Zeng, 2010: The GCM-oriented CALIPSO cloud product (CALIPSO-GOCCP). J. Geophys. Res., 115, D00H16, https://doi.org/10.1029/2009JD012251.

Collins, M., and Coauthors, 2013: Long-term climate change: Projections, commitments and irreversibility. Climate Change 2013: The Physical Science Basis, T. F. Stocker et al., Eds., Cambridge University Press, 1029-1136. 
Dee, D. P., and Coauthors, 2011: The ERA-Interim reanalysis: Configuration and performance of the data assimilation system. Quart. J. Roy. Meteor. Soc., 137, 553-597, https://doi.org/ 10.1002/qj.828.

Deser, C., J. J. Bates, and S. Wahl, 1993: The influence of sea surface temperature gradients on stratiform cloudiness along the equatorial front in the Pacific Ocean. J. Climate, 6, 1172-1180, https:// doi.org/10.1175/1520-0442(1993)006<1172:TIOSST>2.0.CO;2.

Diner, D. J., and Coauthors, 2005: The value of multiangle measurements for retrieving structurally and radiatively consistent properties of clouds, aerosols, and surfaces. Remote Sens. Environ., 97, 495-518, https://doi.org/10.1016/j.rse.2005.06.006.

Eastman, R., and S. G. Warren, 2013: A 39-yr survey of cloud changes from land stations worldwide 1971-2009: Longterm trends, relation to aerosols, and expansion of the tropical belt. J. Climate, 26, 1286-1303, https://doi.org/10.1175/ JCLI-D-12-00280.1.

Fletcher, J. K., S. Mason, and C. Jakob, 2016: A climatology of clouds in marine cold air outbreaks in both hemispheres. J. Climate, 29, 6677-6692, https://doi.org/10.1175/JCLI-D-15-0783.1.

Freeman, E., and Coauthors, 2017: ICOADS Release 3.0: A major update to the historical marine climate record. Int. J. Climatol., 37, 2211-2232, https://doi.org/10.1002/ joc. 4775 .

Garay, M. J., S. P. de Szoeke, and C. M. Moroney, 2008: Comparison of marine stratocumulus cloud top heights in the southeastern Pacific retrieved from satellites with coincident ship-based observations. J. Geophys. Res., 113, D18204, https://doi.org/10.1029/2008JD009975.

Geoffroy, O., S. C. Sherwood, and D. Fuchs, 2017: On the role of the stratiform cloud scheme in the inter-model spread of cloud feedback. J. Adv. Model. Earth Syst., 9, 423-437, https://doi.org/ 10.1002/2016MS000846.

Grise, K. M., and L. M. Polvani, 2014: Southern Hemisphere clouddynamics biases in CMIP5 models and their implications for climate projections. J. Climate, 27, 6074-6092, https://doi.org/ 10.1175/JCLI-D-14-00113.1.

_ and B. Medeiros, 2016: Understanding the varied influence of midlatitude jet position on clouds and cloud radiative effects in observations and global climate models. J. Climate, 29, 9005-9025, https://doi.org/10.1175/JCLI-D-16-0295.1.

_ , and L. M. Polvani, 2016: Is climate sensitivity related to dynamical sensitivity? J. Geophys. Res. Atmos., 121, 5159-5176, https://doi.org/10.1002/2015JD024687.

,,-- G. Tselioudis, Y. Wu, and M. D. Zelinka, 2013: The ozone hole indirect effect: Cloud-radiative anomalies accompanying the poleward shift of the eddy-driven jet in the Southern Hemisphere. Geophys. Res. Lett., 40, 3688-3692, https://doi.org/10.1002/grl.50675.

Grossman, R. L., and A. K. Betts, 1990: Air-sea interaction during an extreme cold air outbreak from the eastern coast of the United States. Mon. Wea. Rev., 118, 324-342, https://doi.org/ 10.1175/1520-0493(1990)118<0324:AIDAEC >2.0.CO;2.

Heidinger, A. K., and M. J. Pavolonis, 2009: Gazing at cirrus clouds for 25 years through a split window. Part I: Methodology. J. Appl. Meteor. Climatol., 48, 1100-1116, https://doi.org/ 10.1175/2008JAMC1882.1.

_ A. T. Evan, M. J. Foster, and A. Walther, 2012: A naive Bayesian cloud-detection scheme derived from CALIPSO and applied within PATMOS-x. J. Appl. Meteor. Climatol., 51, 1129-1144, https://doi.org/10.1175/JAMC-D-11-02.1.

—, M. J. Foster, A. Walther, and X. P. Zhao, 2014: The pathfinder atmospheres-extended AVHRR climate dataset
Bull. Amer. Meteor. Soc., 95, 909-922, https://doi.org/10.1175/ bams-d-12-00246.1.

Hollmann, R., and Coauthors, 2013: The ESA Climate Change Initiative: Satellite data records for essential climate variables. Bull. Amer. Meteor. Soc., 94, 1541-1552, https://doi.org/ 10.1175/BAMS-D-11-00254.1.

Kahn, B. H., and Coauthors, 2014: The Atmospheric Infrared Sounder version 6 cloud products. Atmos. Chem. Phys., 14, 399-426, https://doi.org/10.5194/acp-14-399-2014.

Kay, J. E., B. Medeiros, Y. T. Hwang, A. Gettelman, J. Perket, and M. G. Flanner, 2014: Processes controlling Southern Ocean shortwave climate feedbacks in CESM. Geophys. Res. Lett., 41, 616-622, https://doi.org/10.1002/2013GL058315.

Klein, S. A., and D. L. Hartmann, 1993: The seasonal cycle of low stratiform clouds. J. Climate, 6, 1587-1606, https://doi.org/ 10.1175/1520-0442(1993)006<1587:TSCOLS >2.0.CO;2.

_ , and C. Jakob, 1999: Validation and sensitivities of frontal clouds simulated by the ECMWF model. Mon. Wea. Rev., 127, 2514-2531, https://doi.org/10.1175/1520-0493(1999)127<2514: VASOFC $>2.0 . \mathrm{CO} ; 2$.

, D. L. Hartmann, and J. R. Norris, 1995: On the relationships among low-cloud structure, sea-surface temperature, and atmospheric circulation in the summertime northeast Pacific. J. Climate, 8, 1140-1155., https://doi.org/10.1175/ 1520-0442(1995)008<1140:OTRALC $>2.0$. CO;2.

, A. Hall, J. R. Norris, and R. Pincus, 2017: Low-cloud feedbacks from cloud-controlling factors: A review. Surv. Geophys., 38, 1307-1329, https://doi.org/10.1007/s10712-017-9433-3.

Li, Y., D. W. J. Thompson, G. L. Stephens, and S. Bony, 2014a: A global survey of the instantaneous linkages between cloud vertical structure and large-scale climate. J. Geophys. Res. Atmos., 119, 3770-3792, https://doi.org/10.1002/2013JD020669.

- - , Y. Huang, and M. Zhang, 2014b: Observed linkages between the northern annular mode/North Atlantic Oscillation, cloud incidence, and cloud radiative forcing. Geophys. Res. Lett., 41, 1681-1688, https://doi.org/10.1002/ 2013 GL059113.

- _ - and S. Bony, 2015: The influence of atmospheric cloud radiative effects on the large-scale atmospheric circulation. J. Climate, 28, 7263-7278, https://doi.org/10.1175/ JCLI-D-14-00825.1.

Lipat, B. R., G. Tselioudis, K. M. Grise, and L. M. Polvani, 2017: CMIP5 models' shortwave cloud radiative response and climate sensitivity linked to the climatological Hadley cell extent. Geophys. Res. Lett., 44, 5739-5748, https://doi.org/ 10.1002/2017GL073151.

Loeb, N. G., K. J. Priestley, D. P. Kratz, E. B. Geier, R. N. Green, B. A. Wielicki, P. O. Hinton, and S. K. Nolan, 2001: Determination of unfiltered radiances from the Clouds and the Earth's Radiant Energy System instrument. J. Appl. Meteor., 40, 822-835, https://doi.org/10.1175/1520-0450(2001)040<0822: DOURFT $>2.0 . \mathrm{CO} ; 2$

— B. A. Wielicki, D. R. Doelling, G. L. Smith, D. F. Keyes, S. Kato, N. Manalo-Smith, and T. Wong, 2009: Toward optimal closure of the Earth's top-of-atmosphere radiation budget. J. Climate, 22, 748-766, https://doi.org/10.1175/ 2008JCLI2637.1.

- and Coauthors, 2018: Clouds and the Earth's Radiant Energy System (CERES) Energy Balanced and Filled (EBAF) top-of-atmosphere (TOA) Edition-4.0 data product. J. Climate, 31, 895-918, https://doi.org/10.1175/JCLI-D-17-0208.1.

Mace, G. G., S. Houser, S. Benson, S. A. Klein, and Q. Min, 2011: Critical evaluation of the ISCCP simulator using ground-based 
remote sensing data. J. Climate, 24, 1598-1612, https://doi.org/ 10.1175/2010JCLI3517.1.

Mansbach, D. K., and J. R. Norris, 2007: Low-level cloud variability over the equatorial cold tongue in observations and models. J. Climate, 20, 1555-1570, https://doi.org/10.1175/ JCLI4073.1.

Marchand, R., 2013: Trends in ISCCP, MISR, and MODIS cloud-top-height and optical-depth histograms. J. Geophys. Res. Atmos., 118, 1941-1949, https://doi.org/10.1002/ jgrd.50207.

— , and T. Ackerman, 2010: An analysis of cloud cover in multiscale modeling framework global climate model simulations using 4 and $1 \mathrm{~km}$ horizontal grids. J. Geophys. Res., 115, D16207, https://doi.org/10.1029/2009JD013423.

,-- M. Smyth, and W. B. Rossow, 2010: A review of cloud top height and optical depth histograms from MISR, ISCCP, and MODIS. J. Geophys. Res., 115, D16206, https://doi.org/ 10.1029/2009JD013422.

Marvel, K., M. Zelinka, S. A. Klein, C. Bonfils, P. Caldwell, C. Doutriaux, B. D. Santer, and K. E. Taylor, 2015: External influences on modeled and observed cloud trends. J. Climate, 28, 4820-4840, https://doi.org/10.1175/JCLI-D-14-00734.1.

McGarragh, G. R., and Coauthors, 2018: The Community Cloud retrieval for Climate (CC4CL)_-Part 2: The optimal estimation approach. Atmos. Meas. Tech., 11, 3397-3431, https://doi.org/ 10.5194/amt-11-3397-2018.

Minnis, P., and Coauthors, 2011: Ceres edition-2 cloud property retrievals using TRMM VIRS and Terra and Aqua MODIS data_part I: Algorithms. IEEE Trans. Geosci. Remote Sens., 49, 4374-4400, https://doi.org/10.1109/TGRS.2011.2144601.

Miyamoto, A., H. Nakamura, and T. Miyasaka, 2018: Influence of the subtropical high and storm track on low-cloud fraction and its seasonality over the south Indian Ocean. J. Climate, 31, 4017-4039, https://doi.org/10.1175/ JCLI-D-17-0229.1.

Morcrette, J. J., and Y. Fouquart, 1986: The overlapping of cloud layers in shortwave radiation parameterizations. J. Atmos. Sci., 43, 321-328, https://doi.org/10.1175/1520-0469(1986)043<0321: TOOCLI>2.0.CO;2.

Myers, T. A., and J. R. Norris, 2013: Observational evidence that enhanced subsidence reduces subtropical marine boundary layer cloudiness. J. Climate, 26, 7507-7524, https://doi.org/ 10.1175/JCLI-D-12-00736.1.

— , and — 2015: On the relationships between subtropical clouds and meteorology in observations and CMIP3 and CMIP5 models. J. Climate, 28, 2945-2967, https://doi.org/ 10.1175/JCLI-D-14-00475.1.

— and - 2016: Reducing the uncertainty in subtropical cloud feedback. Geophys. Res. Lett., 43, 2144-2148, https://doi.org/ 10.1002/2015GL067416.

Naud, C. M., J. F. Booth, and A. D. Del Genio, 2016: The relationship between boundary layer stability and cloud cover in the post-cold-frontal region. J. Climate, 29, 8129-8149, https:// doi.org/10.1175/JCLI-D-15-0700.1.

Noda, A. T., and M. Satoh, 2014: Intermodel variances of subtropical stratocumulus environments simulated in CMIP5 models. Geophys. Res. Lett., 41, 7754-7761, https://doi.org/ 10.1002/2014GL061812.

Norris, J. R., 1998a: Low cloud type over the ocean from surface observations. Part I: Relationship to surface meteorology and the vertical distribution of temperature and moisture. J. Climate, 11, 369-382, https://doi.org/10.1175/ 1520-0442(1998)011<0369:LCTOTO>2.0.CO;2.
- 1998b: Low cloud type over the ocean from surface observations. Part II: Geographical and seasonal variations. J. Climate, 11, 383-403, https://doi.org/10.1175/ 1520-0442(1998)011<0383:LCTOTO > 2.0.CO;2.

— ferred from synoptic-scale dynamic and thermodynamic relationships. J. Climate, 18, 4862-4878, https://doi.org/10.1175/ JCLI3558.1.

—, R. J. Allen, A. T. Evan, M. D. Zelinka, C. W. O'Dell, and S. A. Klein, 2016: Evidence for climate change in the satellite cloud record. Nature, 536, 72-75, https://doi.org/10.1038/ nature18273.

Pincus, R., S. Platnick, S. A. Ackerman, R. S. Hemler, and R. J. P. Hofmann, 2012: Reconciling simulated and observed views of clouds: MODIS, ISCCP, and the limits of instrument simulators. J. Climate, 25, 4699-4720, https://doi.org/10.1175/ JCLI-D-11-00267.1.

Qu, X., A. Hall, S. A. Klein, and P. M. Caldwell, 2014: On the spread of changes in marine low cloud cover in climate model simulations of the 21st century. Climate Dyn., 42, 2603-2626, https://doi.org/10.1007/s00382-013-1945-z.

,,--- , and A. M. DeAngelis, 2015: Positive tropical marine low-cloud cover feedback inferred from cloudcontrolling factors. Geophys. Res. Lett., 42, 7767-7775, https://doi.org/10.1002/2015GL065627.

Randall, D. A., 1980: Conditional instability of the first kind upsidedown. J. Atmos. Sci., 37, 125-130, https://doi.org/10.1175/ 1520-0469(1980)037<0125:CIOTFK > 2.0.CO;2.

_ 1987: Turbulent fluxes of liquid water and buoyancy in partly cloudy layers. J. Atmos. Sci., 44, 850-858, https://doi.org/ 10.1175/1520-0469(1987)044<0850:TFOLWA > 2.0.CO;2.

Reynolds, R. W., N. A. Rayner, T. M. Smith, D. C. Stokes, and W. Q. Wang, 2002: An improved in situ and satellite SST analysis for climate. J. Climate, 15, 1609-1625, https://doi.org/ 10.1175/1520-0442(2002)015<1609:AIISAS > 2.0.CO;2.

Rossow, W. B., and R. A. Schiffer, 1999: Advances in understanding clouds from ISCCP. Bull. Amer. Meteor. Soc., 80, 2261-2287, https://doi.org/10.1175/1520-0477(1999)080<2261: AIUCFI $>2.0 . C O ; 2$.

Rozendaal, M. A., C. B. Leovy, and S. A. Klein, 1995: An observational study of diurnal variations of marine stratiform cloud. J. Climate, 8, 1795-1809, https://doi.org/10.1175/ 1520-0442(1995)008<1795:AOSODV>2.0.CO;2.

Salomonson, V. V., W. L. Barnes, P. W. Maymon, H. E. Montgomery, and H. Ostrow, 1989: MODIS: Advanced facility instrument for studies of the Earth as a system. IEEE Trans. Geosci. Remote Sens., 27, 145-153, https://doi.org/10.1109/36.20292.

Seethala, C., J. R. Norris, and T. A. Myers, 2015: How has subtropical stratocumulus and associated meteorology changed since the 1980s? J. Climate, 28, 8396-8410, https://doi.org/ 10.1175/JCLI-D-15-0120.1.

Simpson, I. R., T. A. Shaw, and R. Seager, 2014: A diagnosis of the seasonally and longitudinally varying midlatitude circulation response to global warming. J. Atmos. Sci., 71, 2489-2515, https://doi.org/10.1175/JAS-D-13-0325.1.

Stengel, M., and Coauthors, 2017: Cloud property datasets retrieved from AVHRR, MODIS, AATSR and MERIS in the framework of the Cloud_cci project. Earth Syst. Sci. Data, 9, 881-904, https://doi.org/10.5194/essd-9-881-2017.

Stubenrauch, C. J., and Coauthors, 2013: Assessment of global cloud datasets from satellites: Project and database initiated by the GEWEX Radiation Panel. Bull. Amer. Meteor. Soc., 94, 1031-1049, https://doi.org/10.1175/BAMS-D-12-00117.1. 
Sus, O., and Coauthors, 2018: The Community Cloud retrieval for Climate $(\mathrm{CC} 4 \mathrm{Cl})$-Part 1: A framework applied to multiple satellite imaging sensors. Atmos. Meas. Tech., 11, 3373-3396, https://doi.org/10.5194/amt-11-3373-2018.

Taylor, K. E., 2001: Summarizing multiple aspects of model performance in a single diagram. J. Geophys. Res., 106, 71837192, https://doi.org/10.1029/2000JD900719.

_ R. J. Stouffer, and G. A. Meehl, 2012: An overview of CMIP5 and the experiment design. Bull. Amer. Meteor. Soc., 93, 485498, https://doi.org/10.1175/BAMS-D-11-00094.1.

Terai, C. R., S. A. Klein, and M. D. Zelinka, 2016: Constraining the low-cloud optical depth feedback at middle and high latitudes using satellite observations. J. Geophys. Res. Atmos., 121, 9696-9716, https://doi.org/10.1002/2016JD025233.

Tselioudis, G., B. R. Lipat, D. Konsta, K. M. Grise, and L. M Polvani, 2016: Midlatitude cloud shifts, their primary link to the Hadley cell, and their diverse radiative effects. Geophys. Res. Lett., 43, 4594-4601, https://doi.org/10.1002/2016GL068242.

Voigt, A., and T. A. Shaw, 2015: Circulation response to warming shaped by radiative changes of clouds and water vapour. Nat. Geosci., 8, 102-106, https://doi.org/10.1038/ngeo2345.

Wall, C. J., and D. L. Hartmann, 2015: On the influence of poleward jet shift on shortwave cloud feedback in global climate models. J. Adv. Model. Earth Syst., 7, 2044-2059, https:// doi.org/10.1002/2015MS000520.

Walther, A., and A. K. Heidinger, 2012: Implementation of the daytime cloud optical and microphysical properties algorithm (DCOMP) in PATMOS-x. J. Appl. Meteor. Climatol., 51, 1371-1390, https://doi.org/10.1175/JAMC-D-11-0108.1.

Webb, M., C. Senior, S. Bony, and J. J. Morcrette, 2001: Combining ERBE and ISCCP data to assess clouds in the Hadley Centre, ECMWF and LMD atmospheric climate models. Climate Dyn., 17, 905-922, https://doi.org/10.1007/s003820100157.

Wielicki, B. A., B. R. Barkstrom, E. F. Harrison, R. B. Lee III, G. L. Smith, and J. E. Cooper, 1996: Clouds and the Earth's Radiant Energy System (CERES): An Earth observing system experiment. Bull. Amer. Meteor. Soc., 77, 853-868, https://doi.org/ 10.1175/1520-0477(1996)077<0853:CATERE $>2.0 . C O ; 2$.

Winker, D. M., M. A. Vaughan, A. Omar, Y. Hu, K. A. Powell, Z. Liu, W. H. Hunt, and S. A. Young, 2009: Overview of the CALIPSO mission and CALIOP data processing algorithms. J. Atmos. Oceanic Technol., 26, 2310-2323, https://doi.org/ 10.1175/2009JTECHA1281.1.

Wood, R., and C. S. Bretherton, 2006: On the relationship between stratiform low cloud cover and lower-tropospheric stability. J. Climate, 19, 6425-6432, https://doi.org/10.1175/JCLI3988.1.

Yue, Q., B. H. Kahn, E. J. Fetzer, S. Wong, R. Frey, and K. G. Meyer, 2017: On the response of MODIS cloud coverage to global mean surface air temperature. J. Geophys. Res. Atmos., 122, 966-979, https://doi.org/10.1002/2016JD025174.

Zelinka, M. D., S. A. Klein, and D. L. Hartmann, 2012a: Computing and partitioning cloud feedbacks using cloud property histograms. Part I: Cloud radiative kernels. J. Climate, 25, 3715-3735, https://doi.org/10.1175/JCLI-D-11-00248.1.

,-- , and $-2012 \mathrm{~b}$ : Computing and partitioning cloud feedbacks using cloud property histograms. Part II: Attribution to changes in cloud amount, altitude, and optical depth. J. Climate, 25, 3736-3754, https://doi.org/10.1175/ JCLI-D-11-00249.1.

, C. Zhou, and S. A. Klein, 2016: Insights from a refined decomposition of cloud feedbacks. Geophys. Res. Lett., 43, 92599269, https://doi.org/10.1002/2016GL069917.

Zhang, Y. C., W. B. Rossow, A. A. Lacis, V. Oinas, and M. I. Mishchenko, 2004: Calculation of radiative fluxes from the surface to top of atmosphere based on ISCCP and other global data sets: Refinements of the radiative transfer model and the input data. J. Geophys. Res., 109, D19105, https://doi.org/ 10.1029/2003JD004457.

Zhou, C., M. D. Zelinka, A. E. Dessler, and S. A. Klein, 2015: The relationship between interannual and long-term cloud feedbacks. Geophys. Res. Lett., 42, $10463-10469$, https://doi.org/ 10.1002/2015GL066698. 